\title{
The age again in the eye of the COVID-19 storm: evidence-based decision making
}

\author{
María C. Martín ${ }^{1 \dagger}$, Aurora Jurado $2^{*+} \mathbb{B}$, Cristina Abad-Molina ${ }^{3}$, Antonio Orduña ${ }^{3}$, Oscar Yarce $^{2}$, Ana M. Navas ${ }^{2}$, \\ Vanesa Cunill, Danilo Escobar ${ }^{4}$, Francisco Boix ${ }^{5}$, Sergio Burillo-Sanz ${ }^{5}$, María C. Vegas-Sánchez ${ }^{6}$, \\ Yesenia Jiménez-de las Pozas ${ }^{6}$, Josefa Melero ${ }^{7}$, Marta Aguilar ${ }^{7}$, Oana Irina Sobieschi ${ }^{7}$, Marcos López-Hoyos ${ }^{8}$, \\ Gonzalo Ocejo-Vinyals ${ }^{8}$, David San Segundo ${ }^{8}$, Delia Almeida ${ }^{9}$, Silvia Medina ${ }^{9}$, Luis Fernández ${ }^{10}$, Esther Vergara ${ }^{10}$, \\ Bibiana Quirant ${ }^{11}$, Eva Martínez-Cáceres ${ }^{11}$, Marc Boiges ${ }^{11}$, Marta Alonso ${ }^{12}$, Laura Esparcia-Pinedo ${ }^{13}$, \\ Celia López-Sanz ${ }^{13}$, Javier Muñoz-Vico ${ }^{14}$, Serafín López-Palmero ${ }^{14}$, Antonio Trujillo², Paula Álvarez ${ }^{2}$ Álvaro Prada ${ }^{15}$, \\ David Monzón ${ }^{15}$, Jesús Ontañón ${ }^{16}$, Francisco M. Marco ${ }^{17}$, Sergio Mora ${ }^{17}$, Ricardo Rojo ${ }^{18}$, \\ Gema González-Martínez ${ }^{19}$, María T. Martínez-Saavedra ${ }^{19}$, Juana Gil-Herrera ${ }^{20}$, Sergi Cantenys-Molina ${ }^{20}$, \\ Manuel Hernández ${ }^{21}$, Janire Perurena-Prieto ${ }^{21}$, Beatriz Rodríguez-Bayona ${ }^{22}$, Alba Martínez ${ }^{23}$, Esther Ocaña ${ }^{23}$ and \\ Juan Molina ${ }^{2}$
}

\begin{abstract}
Background: One hundred fifty million contagions, more than 3 million deaths and little more than 1 year of COVID-19 have changed our lives and our health management systems forever. Ageing is known to be one of the significant determinants for COVID-19 severity. Two main reasons underlie this: immunosenescence and age correlation with main COVID-19 comorbidities such as hypertension or dyslipidaemia. This study has two aims. The first is to obtain cut-off points for laboratory parameters that can help us in clinical decision-making. The second one is to analyse the effect of pandemic lockdown on epidemiological, clinical, and laboratory parameters concerning the severity of the COVID-19. For these purposes, 257 of SARSCoV2 inpatients during pandemic confinement were included in this study. Moreover, 584 case records from a previously analysed series, were compared with the present study data.

Results: Concerning the characteristics of lockdown series, mild cases accounted for 14.4, 54.1\% were moderate and $31.5 \%$, severe. There were $32.5 \%$ of home contagions, $26.3 \%$ community transmissions, $22.5 \%$ nursing home contagions, and 8.8\% corresponding to frontline worker contagions regarding epidemiological features. Age > 60 and male sex are hereby confirmed as severity determinants. Equally, higher severity was significantly associated with higher IL6, CRP, ferritin, LDH, and leukocyte counts, and a lower percentage of lymphocyte, CD4 and CD8 count. Comparing this cohort with a previous 584-cases series, mild cases were less than those analysed in the first moment of the pandemic and dyslipidaemia became more frequent than before. IL-6, CRP and LDH values above
\end{abstract}

\footnotetext{
* Correspondence: aurora.jurado.sspa@juntadeandalucia.es

†María C. Martín and Aurora Jurado contributed equally to this work.

${ }^{2}$ Department of Immunology and Allergology, Hospital Universitario Reina

Sofía-Instituto de Investigación Biomédica de Córdoba (IMIBIC), Avd.

Menéndez Pidal s/n, 14004 Córdoba, Spain

Full list of author information is available at the end of the article
}

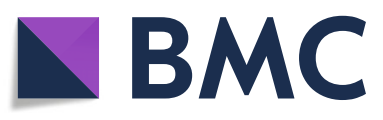

(c) The Author(s). 2021 Open Access This article is licensed under a Creative Commons Attribution 4.0 International License, which permits use, sharing, adaptation, distribution and reproduction in any medium or format, as long as you give appropriate credit to the original author(s) and the source, provide a link to the Creative Commons licence, and indicate if changes were made. The images or other third party material in this article are included in the article's Creative Commons. licence, unless indicated otherwise in a credit line to the material. If material is not included in the article's Creative Commons licence and your intended use is not permitted by statutory regulation or exceeds the permitted use, you will need to obtain permission directly from the copyright holder. To view a copy of this licence, visit http://creativecommons.org/licenses/by/4.0/ The Creative Commons Public Domain Dedication waiver (http://creativecommons.org/publicdomain/zero/1.0/) applies to the data made available in this article, unless otherwise stated in a credit line to the data. 
$69 \mathrm{pg} / \mathrm{mL}, 97 \mathrm{mg} / \mathrm{L}$ and $328 \mathrm{U} / \mathrm{L}$ respectively, as well as a CD4 T-cell count below 535 cells/ $\mathrm{LL}$, were the best cutoffs predicting severity since these parameters offered reliable areas under the curve.

Conclusion: Age and sex together with selected laboratory parameters on admission can help us predict COVID-19 severity and, therefore, make clinical and resource management decisions. Demographic features associated with lockdown might affect the homogeneity of the data and the robustness of the results.

Keywords: Severe acute respiratory syndrome coronavirus 2, COVID-19, Immunosenescence, Lockdown, Immunity, Renin-angiotensin-aldosterone system inhibitors, Cut-off points, Lymphocytes, Area under the curve

\section{Background}

SARS-CoV-2 infection became widespread [1], being possibly the worst trouble worldwide, as its effects have altered virtually any feature in our lives. Health, economy and individual freedom are seriously threatened all around the world. Almost 16 months after the first diagnosed case, several waves and strains have hit global health. The virus has infected 152.974 .685 people and killed 3.204.478 with an overall case-fatality rate of $2.09 \%$ [2]. Identifying risk or severity factors for COVID19 will help clinicians and clinical managers to make decisions about the best therapy [3], and the kind and amount of resources necessary to face new waves [4]. Severity factors might be related to health-based restrictions and should be considered before making public health decisions $[5,6]$.

Since the early days of the pandemic, enormous efforts have been made to identify epidemiological and clinical factors that can predict the severity of the disease [715]. These efforts have firmly established age as one of the crucial elements along with comorbidities closely associated with age, most notably hypertension, diabetes, and obesity [16-23]. Independently, the male sex has also been described to be related to a severe evolution $[16,18-20,22,23]$. Likewise, the analytical parameters related to an exacerbated inflammatory state and an exhausted adaptive immune system have been described in association with the most severe forms [16, 24-26]. Despite the similarity in the overall description of the parameters associated with the severity of COVID-19 disease, there are notable differences in the risk factors and the analytical parameter values, among the articles published [27]. The causes for these differences can rely on the geographical origin of the study populations, the different study designs and the severity criteria adopted. Additionally, some elements, which are not usually reflected in the scientific literature, might influence the pandemic landscape. One of these elements would be the effect of the pandemic lockdown restrictions, with the meaning of "stay-at-home orders" in the patient baseline characteristics. These differences may be especially relevant in defining cut-off points for analytical parameters that could be extrapolated to different populations and different pandemic moments. The objective of this study is twofold. First, to obtain cut-off points for laboratory parameters that can help us in clinical decision-making. Secondly, to evaluate the effect that confinement may have on the patient demographic and clinical characteristics. This study aims to analyse the effect of pandemic lockdown on epidemiological, clinical, and laboratory parameters concerning the severity of the COVID-19; for this purpose, we have compared the baseline demographic and clinical characteristics as related to the severity of COVID-19 inpatients infected before complete lockdown, with those of patients admitted to hospital during close lockdown period.

\section{Results}

A total of 257 inpatients from 13 Spanish Hospitals with SARS-CoV-2 infection were included. Mild cases accounted for $14.4,54.1 \%$ moderate and $31.5 \%$ severe (Table 1), with $32.5 \%$ of home contagions, $26.3 \%$ community transmissions, $22.5 \%$ nursing home contagions and $8.8 \%$ corresponding to frontline workers.

Descriptive baseline characteristics of the population (valid $\mathrm{n}$, frequencies, percentages, mean, median, standard deviation and interquartile range) are shown in Table 1. Categorical variables stratified by severity are shown in Table 2.

Males accounted for $58 \%$ of cases. Ages in our cohort ranged from 18 to 97 years, with a median of 68 years (IQR 54-90). Concerning comorbidities, 16.9\% had obesity, $15.8 \%$ were smoker or ex-smokers, $49.2 \%$ had hypertension, $32.1 \%$ of them were treated with ACEIs (angiotensin converting enzyme inhibitors) and 33\% with ARBs (angiotensin receptor blockers). 41.6\% had dyslipidaemia and $27.6 \%$ suffered diabetes mellitus. The presence of immunodeficiency was most often secondary to other processes, such as a transplantation or chemotherapy treatment; it accounted for $19 \%$ cases $(n=45)$ as seen in Table 1.

Age above $60(p=0.046)$, male gender $(p=0.049)$ and institution or community transmission $(p<0.001)$ arose as severity determinants in our series (Table 2 ). 
Table 1 Baseline characteristics of the study population

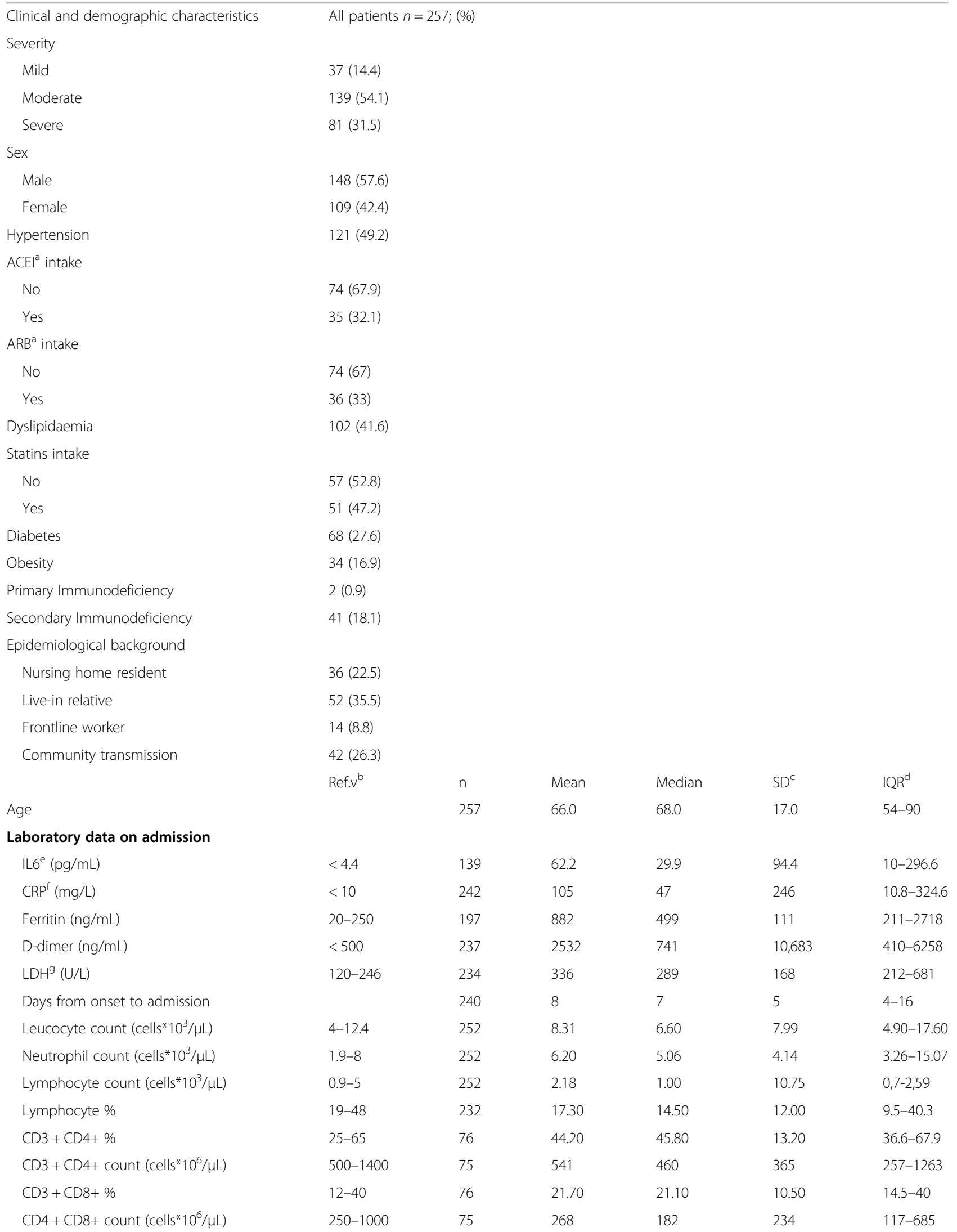


Table 1 Baseline characteristics of the study population (Continued)

\begin{tabular}{|c|c|c|c|c|c|c|}
\hline CD19+ \% & $5-20$ & 68 & 14.20 & 13.30 & 8.30 & $8.1-32.8$ \\
\hline 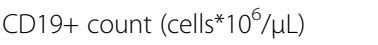 & $100-500$ & 67 & 164 & 127 & 151 & $66-409$ \\
\hline Natural Killer \% & $5-20$ & 68 & 16.30 & 14.40 & 9.00 & $9-36.8$ \\
\hline Natural Killer count (cells*10 $/ \mu \mathrm{L}$ ) & $50-500$ & 64 & 171 & 148 & 107 & $103-335$ \\
\hline Immunoglobulin G (mg/dL) & $650-1600$ & 60 & 961.0 & 924.0 & 431.0 & $728-1629$ \\
\hline Immunoglobulin A (mg/dL) & $40-350$ & 60 & 264.0 & 228.0 & 152.0 & $162-587$ \\
\hline Immunoglobulin M (mg/dL) & $50-300$ & 60 & 105.0 & 89.0 & 83.0 & $70-256$ \\
\hline $\mathrm{C} 3(\mathrm{mg} / \mathrm{dL})$ & & 71 & 133.0 & 127.0 & 46.0 & $108-225$ \\
\hline $\mathrm{C} 4(\mathrm{mg} / \mathrm{dL})$ & & 70 & 30.0 & 28.0 & 13.0 & $23-56$ \\
\hline Total days in hospital & & 245 & 16 & 12 & 11 & $7-38$ \\
\hline
\end{tabular}

Abbreviations: $R A S B^{\mathrm{a}}$ Renin-angiotensin system blockers, Ref. $v^{\mathrm{b}}$ Reference values, $S D^{\mathrm{c}}$ Standard deviation, $I Q R^{\mathrm{d}}$ Interquartile range, IL6 ${ }^{\mathrm{e}}$ Interleukin 6 , $C R P^{\mathrm{f}} C$-reactive protein, $L D H^{\mathrm{g}}$ Lactate dehydrogenase

Neither hypertension nor the use of renin-angiotensin system blockers (RAABs) was significantly associated with severity. Mild cases accounted for $10.1 \%$ of patients with age ranged between 60 and 75 years, and $17.1 \%$ of patients over 75 , whereas only $5.6 \%$ of home nursing cases were mild.

Most comorbidities were age-related, such as hypertension, dyslipidaemia, diabetes and primary immunodeficiency. Smoking status was both age and sex-related (Table 3) (Fig. 1).

On admission, the median of laboratory parameters, IL6, CRP, ferritin, D-dimer and lactate dehydrogenase (LDH) were above reference ranges; but both, percentage and median lymphocyte counts were under reference ranges (Table 1). Higher severity was significantly associated with higher IL6, CRP, ferritin, LDH, and leukocyte counts, and lower percentage and lymphocyte counts (Table 4). Results from 76 cases with data of lymphocyte subpopulations on admission showed that higher severity was significantly associated with lower CD4 and CD8 counts (Table 4).

\section{Comparison of the two series: patients recruited on the very first days of pandemic vs. close confinement}

Our group has previously published data on the risk factors and laboratory parameters of a multicentre series of patients admitted by COVID-19 during the first weeks of the pandemic [16]. A comparison of data corresponding to the close confinement (phase 2 from now on) with the previous series (phase 1 from now on) was performed.

Even with the same inclusion criteria, along with current data and the previous compilation, there were significantly less mild inpatients in phase 2 in comparison with phase $1(p<0.001)$. Age was significantly higher $(p=0.027)$ within the second period. More cases were reported to have dyslipidaemia $(p<0.001)$, a history of secondary immunodeficiency $(p<0.001)$ and fewer patients were on treatment with angiotensin II receptor blockers $(p=0.002)$ (Supplementary Tables 1 and 2).

Laboratory parameters such as IL-6, CRP and ferritin, although increased, were significantly lower during confinement than in the early months of the pandemic $(p=$ $0.028,<0.001$ and $<0.001$ respectively). In contrast, lymphopenia and declining CD8+ cell counts were more evident in the second phase but did not reach significance (Supplementary Table 2).

Severity distribution within male inpatients was almost identical within the two series, but mild female cases decreased as moderate ones grew $(p<0.001$, Fig. 2$)$. Severity was significantly higher for all age groups during confinement, especially within the 60 to 75 years old group. Cases above 75 years were predominantly severe both at the beginning of the pandemic and during confinement. Mild inpatients were older in May $(p=0.01)$ than in March and so were $(p=0.028)$ severe ones (Fig. 3).

Normolipidemic cases were less frequently mild to become moderate in May $(p<0.001)$ as compared to March (Fig. 4).

Regarding raw data stratified by severity, some laboratory parameters such as IL-6, CRP, ferritin and LDH, although high, showed values significantly lower than those in phase one. IL6, CRP and ferritin upon arrival were lower in May moderate cohort and CRP as well in mild inpatients. LDH was lower in May mild group as compared to that of March. In the same line, the lowering of CD8 cell count was more evident in phase two but did not reach the significance. All the other parameters compared yielded similar results in the first and second cohorts (data not shown).

\section{Diagnostic accuracy of laboratory parameters}

To look for cut-off points in laboratory parameters at admission that would allow us to predict the severity of COVID-19 disease, data from the two series of patients were pooled. Kurtosis and asymmetry were calculated 
Table 2 Risk factors by severity n (\%)

\begin{tabular}{|c|c|c|c|}
\hline & $\begin{array}{l}\text { Mild } \\
\text { n (\%) }\end{array}$ & $\begin{array}{l}\text { Moderate } \\
\text { n (\%) }\end{array}$ & $\begin{array}{l}\text { Severe } \\
\text { n (\%) }\end{array}$ \\
\hline \multicolumn{4}{|l|}{ Age $(p=0.046)$} \\
\hline$<30$ & $0(0)$ & $7(87.5)$ & $1(12.5)$ \\
\hline $30-45$ & $3(13)$ & 16(69.6) & $4(17.4)$ \\
\hline $45-60$ & $12(19.7)$ & $36(59)$ & $13(21.3)$ \\
\hline $60-75$ & $9(10.1)$ & $45(50.6)$ & $35(39.3)$ \\
\hline$>75$ & $13(17.1)$ & $35(46.1)$ & $28(36.8)$ \\
\hline \multicolumn{4}{|l|}{ Gender $(p=0.049)$} \\
\hline Male & $21(14.2)$ & $73(49.3)$ & $54(36.5)$ \\
\hline Female & $16(14.7)$ & $66(60.6)$ & $27(24.8)$ \\
\hline \multicolumn{4}{|l|}{ Hypertension } \\
\hline No & $15(12)$ & 74(59.2) & $36(28.8)$ \\
\hline Yes & $19(15.7)$ & $59(48.8)$ & $43(35.5)$ \\
\hline \multicolumn{4}{|l|}{$\mathrm{ACEI}^{\mathrm{a}}$ intake } \\
\hline No & $6(8)$ & $42(56.8)$ & $26(35.1)$ \\
\hline Yes & $7(20)$ & 15(42.9) & $13(37.1)$ \\
\hline \multicolumn{4}{|l|}{$A R B^{b}$ intake } \\
\hline No & $8(11)$ & $37(50.7)$ & $28(38.4)$ \\
\hline Yes & $4(11.1)$ & 19(52.8) & $13(36.1)$ \\
\hline \multicolumn{4}{|l|}{ Dyslipidaemia } \\
\hline No & 19(13.3) & $84(58.7)$ & $40(28)$ \\
\hline Yes & $13(12.7)$ & $49(48)$ & $40(39.2)$ \\
\hline \multicolumn{4}{|l|}{ Statins intake } \\
\hline No & $19(12.8)$ & $88(59.1)$ & $42(28.2)$ \\
\hline Yes & $9(11.3)$ & $39(48.8)$ & $32(40)$ \\
\hline \multicolumn{4}{|l|}{ Diabetes } \\
\hline No & 23(12.9) & 102(57.3) & $53(29.8)$ \\
\hline Yes & $9(13.2)$ & $33(48.5)$ & $26(38.2)$ \\
\hline \multicolumn{4}{|l|}{ Obesity } \\
\hline No & $20(12)$ & $95(56.9)$ & $52(31.1)$ \\
\hline Yes & $3(8.8)$ & $17(50)$ & $14(41.2)$ \\
\hline \multicolumn{4}{|l|}{ Primary Immunodeficiency } \\
\hline No & 27(11.6) & 130(55.8) & $76(32.6)$ \\
\hline Yes & $0(0)$ & $2(100)$ & $0(0)$ \\
\hline \multicolumn{4}{|c|}{ Secondary Immunodeficiency } \\
\hline No & 23(12.4) & 103(55.7) & $59(31.9)$ \\
\hline Yes & $3(7.3)$ & $24(58.5)$ & $14(34.1)$ \\
\hline \multicolumn{4}{|c|}{ Epidemiological background $(p=0.001)$} \\
\hline Nursing home resident & $2(5.6)$ & 19(52.8) & $15(41.7)$ \\
\hline Live-in relative & 10(19.2) & $37(71.2)$ & $5(9.6)$ \\
\hline Frontline worker & $0(0)$ & 11(78.6) & $3(21.4)$ \\
\hline Community transmission & $6(14.3)$ & 16(38.1) & $20(47.6)$ \\
\hline
\end{tabular}

Abbreviations: $A C E I^{\mathrm{a}}$ Angiotensin-converting enzyme inhibitors, $A R B^{\mathrm{b}}$ Angiotensin II receptor blockers for both cohorts and both fell apart $>10 \%$ for every parameter but age, lymphocyte count and LDH. In terms of diagnostic accuracy, only IL-6, CRP, LDH levels and lymphocyte CD4+ count offered a reliable area under the curve. The optimal cut-off and the diagnostic statistics for each parameter are shown in Table 5. Moreover, two extreme thresholds were determined in the merged cohort. A threshold with a likelihood ratio positive (LR+ ) appropriate for predicting severe COVID-19 and a point with a likelihood ratio negative (LR-) suitable for discarding severe COVID-19 was calculated. Extreme cut-offs for each parameter are shown in Table 5. When assessing diagnostic accuracy, CD19 count had an unacceptable AUC of 0.59 (95\% CI: 0.47-0.71).

\section{Discussion}

This study raises the question of whether the decision values for both clinical and laboratory parameters associated with severe COVID-19 might change, depending on external or environmental factors such as lockdown. Even working with the same population, selection criteria, and observers, a certain degree of data heterogeneity arises and searching for prognostic risk factors or laboratory cut-off values becomes troublesome. Noise factors should be therefore discarded to simplify and improve triage algorithms.

Regarding severity of SARS-CoV-2 infection, different risk factors or comorbidities and laboratory parameters have been reported to date, but none of them is consistent across published studies [27]. Our group has previously described the relationship among demographic, clinical and laboratory parameters with COVID-19 severity in a retrospective study including 584 patients infected for SARS-CoV-2, just before the alarm state declaration and the close confinement in our country in March 2020 [16]. In the present work, with the same case selection and severity criteria, we describe the relationship between clinical risk factors and laboratory parameters at admission in a group of 257 patients admitted to Spanish hospitals during confinement in May 2020.

Concerning clinical risk factors found at the first moment (age, male sex, hypertension, diabetes, hyperlipidaemia, ARBs intake) only age and male sex remain relevant in this second moment. The epidemiological background, which was not recorded in the first phase, was a risk factor for severest COVID-19. Laboratory parameters such as leukocytes, neutrophils, IL-6, CRP, ferritin, D-dimer, and LDH increased with the severity conversely to the decrease in lymphocyte percentage.

However, as comparing both cohorts, severity, and the presence of comorbidities such as dyslipidaemia and secondary immunodeficiency (SID) was significantly higher 
Table 3 Influence of age and gender on comorbidities

\begin{tabular}{|c|c|c|c|c|c|c|c|}
\hline \multirow{3}{*}{ 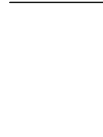 } & \multicolumn{5}{|l|}{ Age } & \multicolumn{2}{|l|}{ Gender } \\
\hline & $<30$ & $30-45$ & $45-60$ & $60-75$ & $>75$ & Male & Female \\
\hline & n (\%) & n (\%) & n (\%) & n (\%) & n (\%) & n (\%) & n (\%) \\
\hline \multicolumn{8}{|c|}{ Hypertension $^{a}$} \\
\hline No & $7(5.6)$ & 19(15.2) & $41(32.8)$ & $41(32.8)$ & 17(13.6) & $67(53.6)$ & $58(46.4)$ \\
\hline Yes & $0(0)$ & $2(1.7)$ & $17(14)$ & $45(37.2)$ & $57(47.1)$ & $73(60.3)$ & $48(39.7)$ \\
\hline \multicolumn{8}{|c|}{ Dyslipidaemia $^{a}$} \\
\hline No & $7(4.9)$ & $17(11.9)$ & $45(31.5)$ & $47(32.9)$ & $27(18.9)$ & $81(56.6)$ & $62(43.4)$ \\
\hline Yes & $0(0)$ & 4(3.9) & $15(14.7)$ & $38(37.3)$ & $45(44.1)$ & $59(57.8)$ & $43(42.2)$ \\
\hline \multicolumn{8}{|c|}{ Obesity } \\
\hline No & $5(3)$ & $14(8.4)$ & $42(25.1)$ & $56(33.5)$ & $50(29.9)$ & 103(61.7) & 64(38.3) \\
\hline Yes & $1(2.9)$ & $2(5.9)$ & $7(20.6)$ & $18(52.9)$ & $6(17.6)$ & $17(50)$ & $17(50)$ \\
\hline \multicolumn{8}{|c|}{ Diabetes $^{a}$} \\
\hline No & $7(3.9)$ & 18(10.1) & $55(30.9)$ & $57(32)$ & $41(23)$ & $102(57.3)$ & $76(42.7)$ \\
\hline Yes & $0(0)$ & $3(4.4)$ & $5(7.4)$ & $31(45.6)$ & $29(42.6)$ & 40(58.8) & $28(41.2)$ \\
\hline \multicolumn{8}{|c|}{ Smoker ${ }^{a, b}$} \\
\hline No & $4(2.2)$ & $17(9.1)$ & $50(26.9)$ & $65(34.9)$ & $50(26.9)$ & $101(54.3)$ & $85(45.7)$ \\
\hline Yes & $3(12)$ & $1(4)$ & $7(28)$ & $6(24)$ & $8(32)$ & $20(80)$ & $5(20)$ \\
\hline Ex & $0(0)$ & $0(0)$ & $0(0)$ & $8(80)$ & $2(20)$ & $8(80)$ & $2(20)$ \\
\hline \multicolumn{8}{|c|}{ Primary immunodeficiency ${ }^{a}$} \\
\hline No & $7(3)$ & 21(9) & $59(25.3)$ & $83(35.6)$ & $63(27)$ & 133(57.1) & $100(42.9)$ \\
\hline Yes & $1(50)$ & $0(0)$ & $0(0)$ & $0(0)$ & $1(50)$ & $1(50)$ & $1(50)$ \\
\hline \multicolumn{8}{|c|}{ Secundary immunodeficiency } \\
\hline No & $5(2.7)$ & 16(8.6) & $52(28.1)$ & $60(32.4)$ & $52(28.1)$ & $98(53)$ & $87(47)$ \\
\hline Yes & $2(4.9)$ & $3(7.3)$ & $6(14.6)$ & $21(51.2)$ & $9(22)$ & $28(68.3)$ & 13(31.7) \\
\hline \multicolumn{8}{|c|}{ Epidemiological background } \\
\hline $\mathrm{NHR}$ & $1(2.8)$ & $3(8.3)$ & $6(16.7)$ & $8(22.2)$ & $18(50)$ & $18(50)$ & $18(50)$ \\
\hline LIR & $1(1.9)$ & $5(9.6)$ & $15(28.8)$ & $16(30.8)$ & $15(28.8)$ & $31(59.6)$ & $21(40.4)$ \\
\hline FW & $1(7.1)$ & $1(7.1)$ & $7(50)$ & $4(28.6)$ & $1(7.1)$ & $5(35.7)$ & $9(64.3)$ \\
\hline$C T$ & $3(6.7)$ & $7(15.6)$ & $12(26.7)$ & 23(51.1) & $13(51.1)$ & $38(65.5)$ & $20(34.5)$ \\
\hline
\end{tabular}

All $p$-values either age ${ }^{\mathrm{a}}$ or gender $^{\mathrm{b}}$ were $<0.001$

Abbreviations: NHR Nursing home resident, LIR Live-in relative, FW Frontline worker, CT Community transmission

in patients hospitalized during confinement while the use of ARBs was significantly lower.

Strikingly, IL-6, CRP and ferritin, whose elevations were associated with greater severity in both phases, were lower in this second phase than in the first one. There is no straightforward explanation for this finding. One of the major differences that could be a decisive factor is that cases included in the first series were infected just before strict containment measures were enacted in Europe. Meanwhile, cases included in the second series were admitted during close confinement. We may guess that during strict confinement, the epidemiological background would have been oscillating to institutional contagions. In the second phase, the epidemiological background was recorded, and it is worth noticing that $25 \%$ of the cases were institutionalized in nursing homes. A higher number of institutionalized cases would mainly impact data because of their older age and a higher rate of second-stage patients' preexisting morbidities. In turn, the relative weight of the age-associated factors might be even higher in this series. Therefore, the relative weight of other factors, such as those associated with the viral infection, might be lower. Additionally, medical prescribing habits for such as the use of RAASBs might have been influenced either by institutionalization or by the highly changing huge number of variable-quality scientific reports at the beginning of pandemics.

A remarkable effort has been made to identify clinical and laboratory factors that can help us predict the 


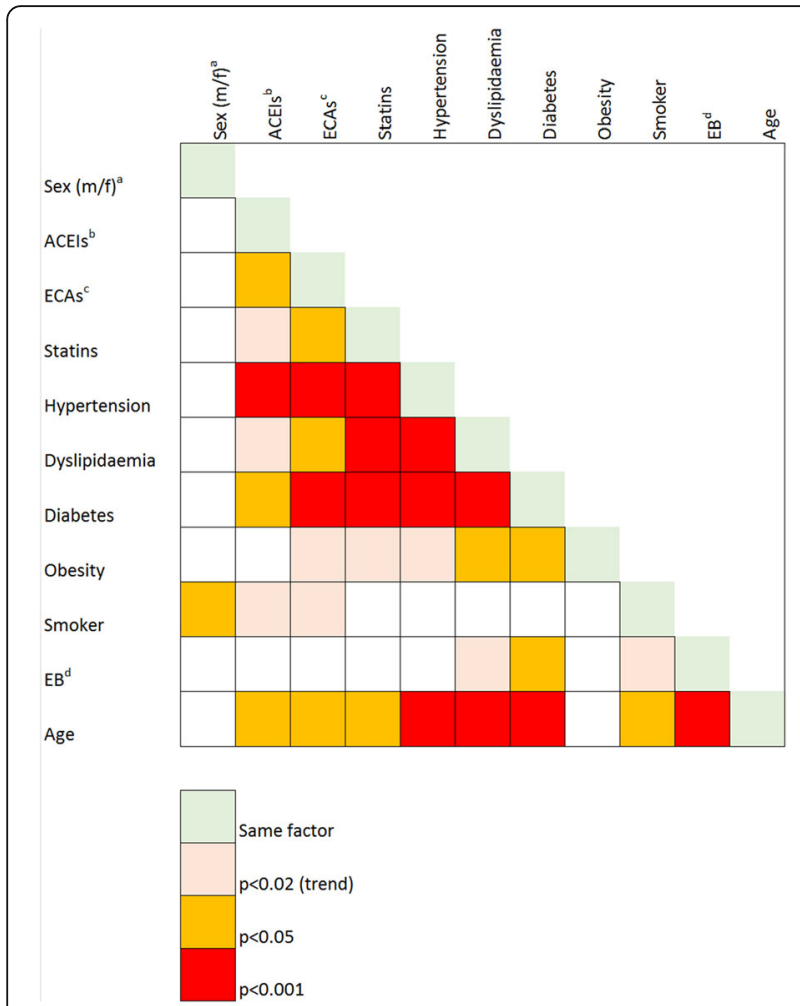

Fig. 1 Severity factors and comorbidities interactions. Legend. Pearson's Chi Squared $p$-values. Abbreviations: Sex(m/f): Sex (male/ female); $\mathrm{ACEl}^{\mathrm{b}}$ : angiotensin conversor enzyme inhibitors; $\mathrm{ARBs}^{\mathrm{c}}$ : angiotensin II receptor blockers; $\mathrm{EB}^{\mathrm{d}}$ : epidemiological background

evolution of COVID-19 disease. This effort crystallized in a vast amount of original articles and meta-analyses. As in our previous study, in most meta-analyses, age, as well as the presence of hypertension, diabetes and cardiovascular disease, are identified as COVID-19 risk factors $[17,18]$. Regarding laboratory data upon admission, in line with our findings, several studies reveal a significant increase in IL-6 [17, 27-29], CRP [17, 27-29], Ddimer [17, 18, 27, 28], ferritin [17, 29], LDH [17, 18], leukocytes [17, 28, 29], neutrophils [27-29], and a decrease of lymphocytes [17, 18, 27-30], a decrease of T lymphocytes CD4+ $[27,29,30]$ and CD $8+[18,27,29$, $30]$, related to the severity. However, in some of these papers $[17,28]$ the authors warn about heterogeneity across different studies selected for meta-analysis, pointing out as possible causes the origin of the data, the sample size and the month of publication.

In our current work, some previously identified factors associated with severity along the first period lost their significant relationships while age and gender were consolidated as severity factors. In addition to remark, age remains a determinant of the main comorbidities initially identified as risk factors. Furthermore, significant quantitative differences within laboratory values have been detected as comparing both periods, pointing out a temporal bias.
Particular attention has been paid as well to clarify the role of RAASBs in SARS-CoV-2 infection and the severity of COVID-19 disease. Several meta-analyses have addressed this central issue, but no consensus is met to date. An overall protective effect of RAASBs use is described, this would be mainly attributable to the use of ACEIs (OR:0.652; 95\% CI: 0.478-0.891), but not similar effect is observed with concomitant ACEIs plus ARBs (OR:0.867; 95\% IC:0.638-1.179) or ARBs alone intakes (OR:0.810; 95\% IC:0.629-1.044) [31]. In another meta-analysis where the relationship of the use of RAASBs with the probability of COVID-19 is stated, geographical differences are evidenced, detecting that the use of RAASBs is generally associated with a better prognosis only in studies carried out in Asian countries (OR.0.37; 95\% CI: 0.16-0.89) whereas, in those carried out in North America, it is commonly associated with an even more significant increase in ICU admissions (OR: 1.75; 95\% CI: $1.37-2.23$ ) and in those carried out in Europe it is related with a higher death probability (OR: 1.68; 95\% CI: 1.05-2.70). The authors note that ACEIs would be mainly protective and conversely, ARBs would be associated with an increased risk of death [32]. In a different sense are the findings of the meta-analyses of Megaly et al. [33] and Chan et al. [34]. In the first one, the use of RAASBs is associated with a lower risk of death (OR: 0.57; 95\% CI: 0.32-0.98) [33]. In the latter, the use of RAASBs is not globally associated with an increased risk of infection (ACEIs OR: 0.95; 95\% CI: 0.861.05), (ARBs OR: 1.05; 95\% CI: 0.97-1.14) [34]. However, ARBs increase the risk of infection in young subjects, while ACEIs do not increase the susceptibility to infection, not the severity or mortality from COVID-19 [34]. In the phase 1 of our study, a protective effect promoted by ACE inhibitors' intake was described, while the use of ARBs was associated with increased severity [16]. However, our current study does not find any effect of the use of RAAS inhibitors, neither protection nor higher risk. Due to the widespread use of this drug and the apparent beneficial effects concerning COVID-19 disease of ACEIs compared with the deleterious effect of ARBs, more controlled studies are necessary to delve into this major concern.

In order to search for cut-off points of laboratory parameters at the time of admission, which would help us predict the evolution of the patients, data from both series were merged. In terms of diagnostic accuracy, only IL-6, LDH, CRP and CD4 + lymphocyte counts offered an acceptable area under the curve (Table 5).

Accordingly, the extreme threshold values that would allow us to confirm or rule out a serious evolution, for these parameters or the NK count were only informative. On the other hand, leukocyte, neutrophil and lymphocyte counts, although predictable, yielded cut-off points with adequate $\mathrm{LR}+$, that could help foresee a severe evolution. 
Table 4 Age and Laboratory results by COVID-19 severity

\begin{tabular}{|c|c|c|c|c|c|c|}
\hline & Severity $p$-value & $\mathrm{n}$ & Mean & Median & $S D^{a}$ & $\mathrm{IQR}^{\mathbf{b}}$ \\
\hline Age & 0.002 & & & & & \\
\hline Mild & & 37 & 68.22 & 68 & 16.64 & $54-82$ \\
\hline Moderate & & 138 & 62.87 & 66 & 16.84 & $49.32-76$ \\
\hline Severe & & 80 & 70.59 & 70 & 13.19 & $61.5-80.5$ \\
\hline \multicolumn{7}{|l|}{ On admission } \\
\hline $\operatorname{IL} \sigma^{\mathrm{c}}(\mathrm{pg} / \mathrm{mL})$ & $<0.001$ & & & & & \\
\hline Mild & & 11 & 25.01 & 10.6 & 32.31 & $5.2-37.1$ \\
\hline Moderate & & 88 & 44.85 & 29.46 & 56.46 & $8.41-56.5$ \\
\hline Severe & & 40 & 110.47 & 43.45 & 143.75 & $20.05-143.62$ \\
\hline $\mathrm{CRP}^{\mathrm{d}}(\mathrm{mg} / \mathrm{L})$ & 0.006 & & & & & \\
\hline Mild & & 34 & 43.87 & 22.35 & 54.88 & $8.16-58.4$ \\
\hline Moderate & & 135 & 80.74 & 37.8 & 200.46 & $6.8-103.75$ \\
\hline Severe & & 73 & 177.13 & 100.6 & 344.21 & 43.3-195.3 \\
\hline Ferritin $(\mathrm{ng} / \mathrm{mL})$ & 0.002 & & & & & \\
\hline Mild & & 22 & 474.00 & 256.8 & 540.30 & $197-535$ \\
\hline Moderate & & 120 & 731.87 & 459.75 & 907.18 & $181-925$ \\
\hline Severe & & 55 & 1373.10 & 929 & 1488.30 & 366.4-1805 \\
\hline \multicolumn{7}{|l|}{ D-dimer (ng/mL) } \\
\hline Mild & & 30 & 1234.90 & 684 & 2069.30 & $373-1297$ \\
\hline Moderate & & 134 & 1652.22 & 715.5 & 5786.79 & $431-1150$ \\
\hline Severe & & 73 & 4680.19 & 800 & $17,425.42$ & $462-1990$ \\
\hline $\mathrm{LDH}^{\mathrm{e}}(\mathrm{U} / \mathrm{L})$ & $<0.001$ & & & & & \\
\hline Mild & & 31 & 215.39 & 206 & 62.63 & $172-243$ \\
\hline Moderate & & 128 & 328.92 & 287 & 160.07 & $213.5-408.5$ \\
\hline Severe & & 75 & 396.96 & 354 & 183.43 & $263-507$ \\
\hline Leucocyte count (cells*103/ $/ \mu \mathrm{L}$ ) & 0.011 & & & & & \\
\hline Mild & & 34 & 424.62 & 6.39 & 1813.47 & $5.53-8.78$ \\
\hline Moderate & & 137 & 190.92 & 6.37 & 1098.34 & $4.6-8.75$ \\
\hline Severe & & 81 & 280.85 & 8.25 & 1441.86 & $5.5-12.98$ \\
\hline \multicolumn{7}{|l|}{ Neutrophil count (cells* $10^{3} / \mu \mathrm{L}$ ) } \\
\hline Mild & & 34 & 286.69 & 4.85 & 1244.32 & $3-6.85$ \\
\hline Moderate & & 137 & 129.54 & 4.8 & 782.33 & $3.17-7$ \\
\hline Severe & & 81 & 220.16 & 7 & 1147.11 & $4.19-11.58$ \\
\hline Lymphocyte count (cells*10 $10^{3} / \mu \mathrm{L}$ ) & 0.005 & & & & & \\
\hline Mild & & 34 & 1.44 & 1.29 & 0.78 & $0,84-1,78$ \\
\hline Moderate & & 137 & 2.1 & 1.06 & 9.07 & $0,7-1,39$ \\
\hline Severe & & 81 & 1 & 0.91 & 0.59 & $0,68-1,15$ \\
\hline Lymphocyte \% & 0.005 & & & & & \\
\hline Mild & & 34 & 21.92 & 18.85 & 12.74 & $14-28.2$ \\
\hline Moderate & & 119 & 18.82 & 15 & 12.64 & $10.9-25$ \\
\hline Severe & & 79 & 13.10 & 11 & 9.27 & $6.6-16.7$ \\
\hline
\end{tabular}


Table 4 Age and Laboratory results by COVID-19 severity (Continued)

\begin{tabular}{|c|c|c|c|c|c|c|}
\hline & Severity $p$-value & $\mathrm{n}$ & Mean & Median & $S D^{a}$ & $\mathrm{IQR}^{\mathrm{b}}$ \\
\hline \multicolumn{7}{|l|}{$\mathrm{CD} 3+\mathrm{CD} 4+\%$} \\
\hline Mild & & 9 & 51.17 & 51 & 11.79 & $43.1-56.7$ \\
\hline Moderate & & 48 & 43.88 & 45.76 & 12.71 & $37.43-51.525$ \\
\hline Severe & & 19 & 41.78 & 41 & 14.46 & $34.32-52.74$ \\
\hline CD3 + CD $4+$ count (cells* $\left.10^{3} / \mu \mathrm{L}\right)$ & 0.007 & & & & & \\
\hline Mild & & 9 & 729.87 & 565 & 445.12 & $372.015-1035$ \\
\hline Moderate & & 48 & 586.66 & 516 & 365.49 & $289.252-818.5$ \\
\hline Severe & & 18 & 325.35 & 293 & 210.64 & 185.934-466.519 \\
\hline \multicolumn{7}{|l|}{$\mathrm{CD} 3+\mathrm{CD} 8+\%$} \\
\hline Mild & & 9 & 20.45 & 24.4 & 10.09 & $14.79-27.1$ \\
\hline Moderate & & 48 & 21.95 & 21.84 & 9.48 & $14.83-27.05$ \\
\hline Severe & & 19 & 21.71 & 18 & 13.23 & $12.34-28.9$ \\
\hline CD $4+$ CD $8+$ count (cells* $\left.* 10^{3} / \mu \mathrm{L}\right)$ & 0.018 & & & & & \\
\hline Mild & & 9 & 263.29 & 177 & 205.19 & $143.616-269.955$ \\
\hline Moderate & & 48 & 283.92 & 214 & 195.35 & $132.5-412.5$ \\
\hline Severe & & 18 & 226.03 & 129.22 & 331.47 & $82-228$ \\
\hline \multicolumn{7}{|l|}{ CD19+ \% } \\
\hline Mild & & 9 & 12.08 & 12.76 & 5.00 & $9.8-15.8$ \\
\hline Moderate & & 44 & 13.98 & 13.47 & 7.91 & $7.4-17.18$ \\
\hline Severe & & 15 & 16.16 & 14.5 & 10.81 & $9-20.68$ \\
\hline \multicolumn{7}{|l|}{ CD19+ count (cells $\left.{ }^{*} 10^{3} / \mu \mathrm{L}\right)$} \\
\hline Mild & & 9 & 166.59 & 145 & 108.67 & $76.23-241.74$ \\
\hline Moderate & & 44 & 177.19 & 130 & 168.64 & $66.5-217.966$ \\
\hline Severe & & 14 & 120.52 & 114.85 & 108.90 & $66-132.936$ \\
\hline \multicolumn{7}{|l|}{ Natural Killer \% } \\
\hline Mild & & 9 & 12.91 & 11 & 6.85 & $7.7-15$ \\
\hline Moderate & & 44 & 16.85 & 14.63 & 9.24 & $9.205-20.75$ \\
\hline Severe & & 15 & 16.93 & 17.06 & 9.66 & $8.36-23.8$ \\
\hline \multicolumn{7}{|l|}{ Natural Killer count (cells* $10^{3} / \mu \mathrm{L}$ ) } \\
\hline Mild & & 9 & 159.68 & 132 & 89.67 & $103-169$ \\
\hline Moderate & & 41 & 188.59 & 157 & 116.15 & $119-223$ \\
\hline Severe & & 14 & 126.01 & 127.9 & 75.10 & $66-188$ \\
\hline \multicolumn{7}{|l|}{$\lg G(\mathrm{mg} / \mathrm{dL})$} \\
\hline Mild & & 9 & 853.84 & 918 & 212.83 & $782-980$ \\
\hline Moderate & & 31 & 981.27 & 950.3 & 296.30 & 772.14-1190 \\
\hline Severe & & 20 & 976.96 & 821 & 642.17 & $618.255-1048.5$ \\
\hline \multicolumn{7}{|l|}{$\lg A(m g / d L)$} \\
\hline Mild & & 9 & 284.40 & 239 & 206.15 & $175-277$ \\
\hline Moderate & & 31 & 278.63 & 251 & 133.13 & $184.85-358$ \\
\hline Severe & & 20 & 232.88 & 189.97 & 154.48 & $152.5-311$ \\
\hline $\lg M(m g / d L)$ & 0.009 & & & & & \\
\hline Mild & & 9 & 164.57 & 94 & 175.42 & 86.3-133 \\
\hline Moderate & & 31 & 103.63 & 98.7 & 53.67 & 71.59-132 \\
\hline Severe & & 20 & 81.39 & 84 & 43.07 & $46.45-112.95$ \\
\hline
\end{tabular}


Table 4 Age and Laboratory results by COVID-19 severity (Continued)

\begin{tabular}{|c|c|c|c|c|c|c|}
\hline & Severity $p$-value & $n$ & Mean & Median & $S D^{a}$ & $I_{Q} R^{b}$ \\
\hline \multicolumn{7}{|l|}{ C3 (mgdL) } \\
\hline Mild & & 8 & 142.80 & 139 & 25.72 & $125-151.68$ \\
\hline Moderate & & 38 & 135.03 & 127 & 50.55 & $108-152$ \\
\hline Severe & & 25 & 126.91 & 125 & 44.84 & $90-153.28$ \\
\hline \multicolumn{7}{|l|}{ C4 (mgdL) } \\
\hline Mild & & 8 & 31.58 & 29.5 & 5.26 & 28.4-33.85 \\
\hline Moderate & & 37 & 30.52 & 29.3 & 11.72 & $23-39$ \\
\hline Severe & & 25 & 28.30 & 25.7 & 15.40 & $23-29.8$ \\
\hline
\end{tabular}

Abbreviations: $S D^{\mathrm{a}}$ Standard deviation, $I Q R^{\mathrm{b}}$ Interquartile range, $I L 6^{\mathrm{c}}$ Interleukin $6, C R P^{\mathrm{d}}$ C-reactive protein, $L D H^{\mathrm{e}}$ Lactate dehydrogenase

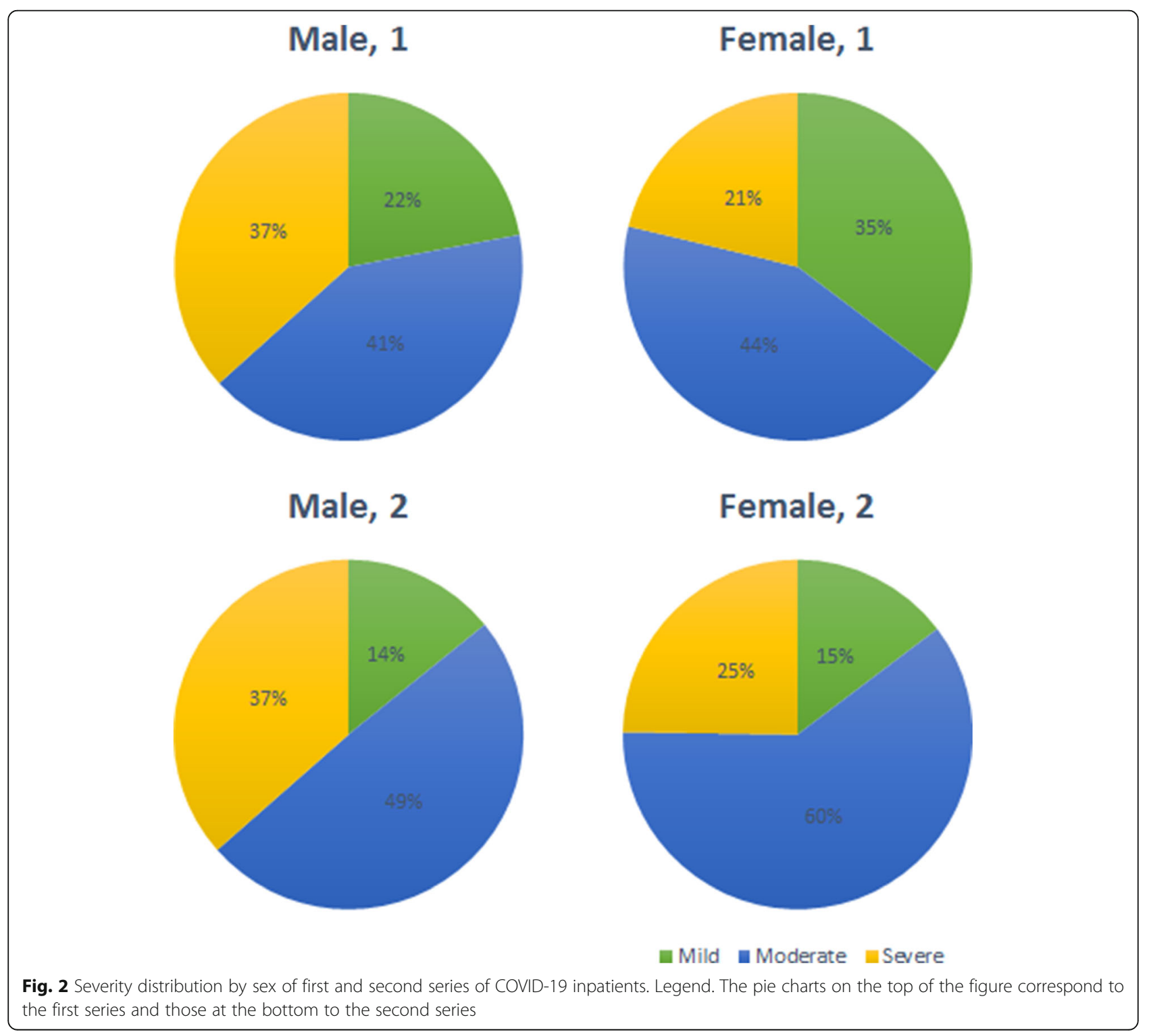




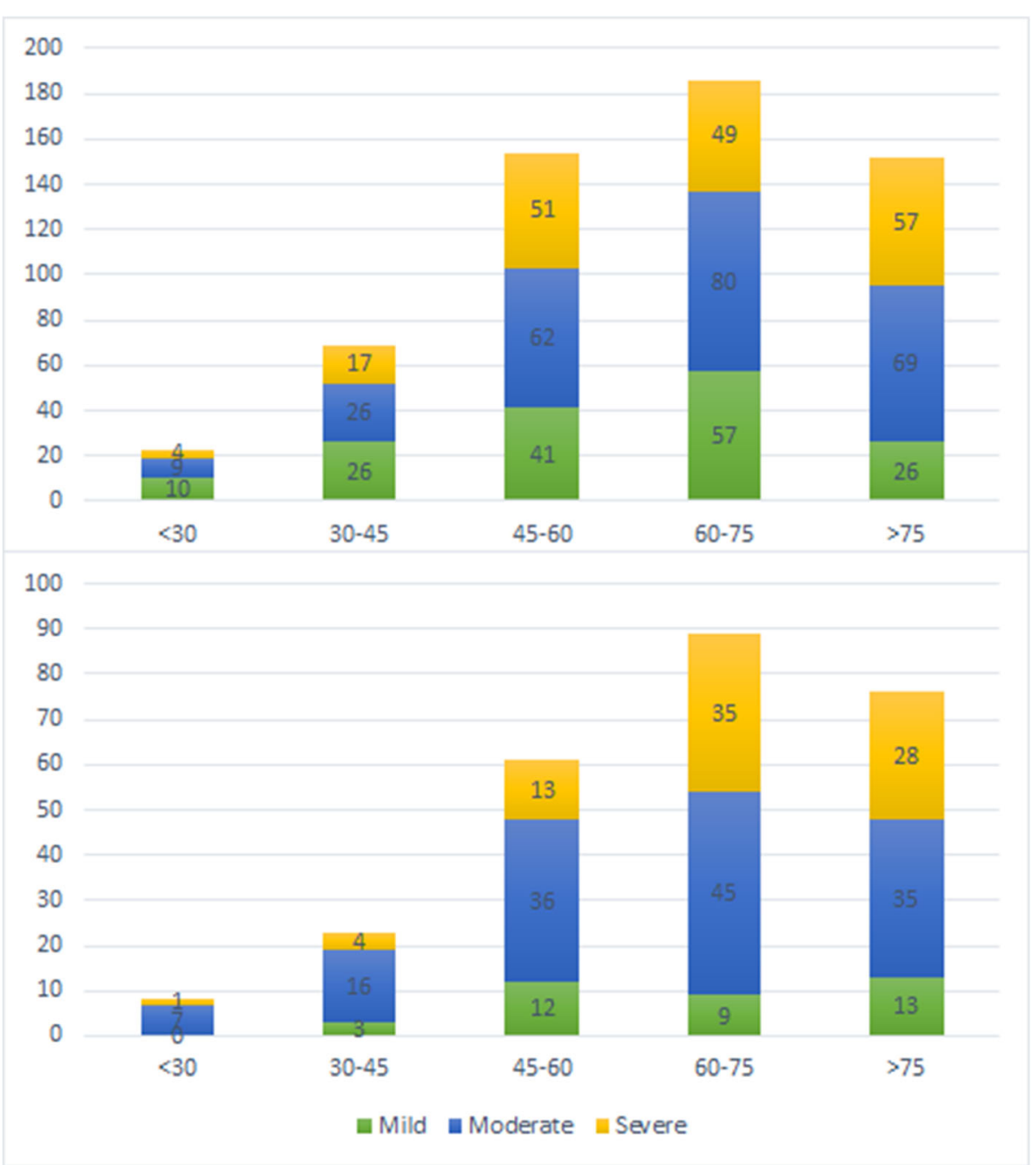

Fig. 3 Severity distribution by age groups of first and second series of COVID-19 inpatients. Legend. The upper part of the figure corresponds to the first series and the lower part to the second series

Several studies analyse the ability of cut-off points in laboratory parameters to predict the evolution of COVID-19. For LDH, several cut-off points have been described. LDH (250-500 U/L) (HR 2.5, 95\% CI 1.2-5.2) and $\mathrm{LDH}>500 \mathrm{U} / \mathrm{L}(\mathrm{HR} 9.8,95 \% \mathrm{CI} 2.8-33.8)$ [20]; LDH $>277 \mathrm{U} / \mathrm{L}$ (sensitivity $58.7 \%$, specificity $82 \%$ for severe disease) and $359.5 \mathrm{U} / \mathrm{L}$ (sensitivity $93.8 \%$, specificity $88.2 \%$ for death) [35]; LDH $>450 \mathrm{U} / \mathrm{L}$ (AUC 0.76, sensitivity $75 \%$, specificity $70 \%$ ) for respiratory failure) [36]; $\mathrm{LDH}>325 \mathrm{U} / \mathrm{L}$ (AUC 0.762 for severe disease) [23]. In our study the optimal cut-off for LDH was similar to those previously described, 328.5 U/L (AUC 0.71, 95\% CI:0.67-0.75) (Sensitivity: 66.6\%; Specificity: 75.2\%) for severe disease (Table 5). Additionally, two extreme thresholds were calculated; the value $574 \mathrm{IU} / \mathrm{L}$ had an $\mathrm{LR}+$ of 5.3 for diagnosing severe disease, and a value of 177.5 IU/L had an LR- of 0.30 for discarding severe COVID-19.
Several cut-off points have been described for the CRP. A value of $11 \mu \mathrm{g} / \mathrm{dL}$ showed an AUC of 0.78 (sensitivity $72 \%$, specificity $71 \%$ ) for respiratory failure [36]; CRP $>25.95 \mathrm{mg} / \mathrm{L}$ has an AUC of 0.84 (95\% CI 0.7800.905) for severity [37]; CRP $>46 \mathrm{mg} / \mathrm{L}$ has an AUC of 0.777 for severity [23]; CRP $>38.2 \mathrm{mg} / \mathrm{L}$ has and AUC of 0.875 (95\% CI $0.867-0.883$ ) (sensitivity $84.6 \%$, Specificity 92.3\%) for severity [28]. In our study the optimal CRP cut-off was higher than those previously published, 97.3 $\mathrm{mg} / \mathrm{L}$ (AUC 0.69, 95\% CI 0.65-0.73) (Sensitivity: 62.2\%; Specificity: 66.1\%) (Table 5). Concerning the extreme thresholds, the value $291.85 \mathrm{mg} / \mathrm{L}$ had an $\mathrm{LR}+$ of 5.16 for diagnosing severe disease and a value of $7 \mathrm{mg} / \mathrm{L}$ had an LR- of 0.21 for discarding severe COVID-19.

Like other acute phase reactants, ferritin is elevated in the moderate and severe forms of COVID-19. Tahtasa$\mathrm{kal}$ et al. have proposed a ferritin value $>303 \mu \mathrm{g} / \mathrm{L}$ (303 $\mathrm{ng} / \mathrm{mL}$ ) (AUC 0.698) as a predictor of severity [23]. 


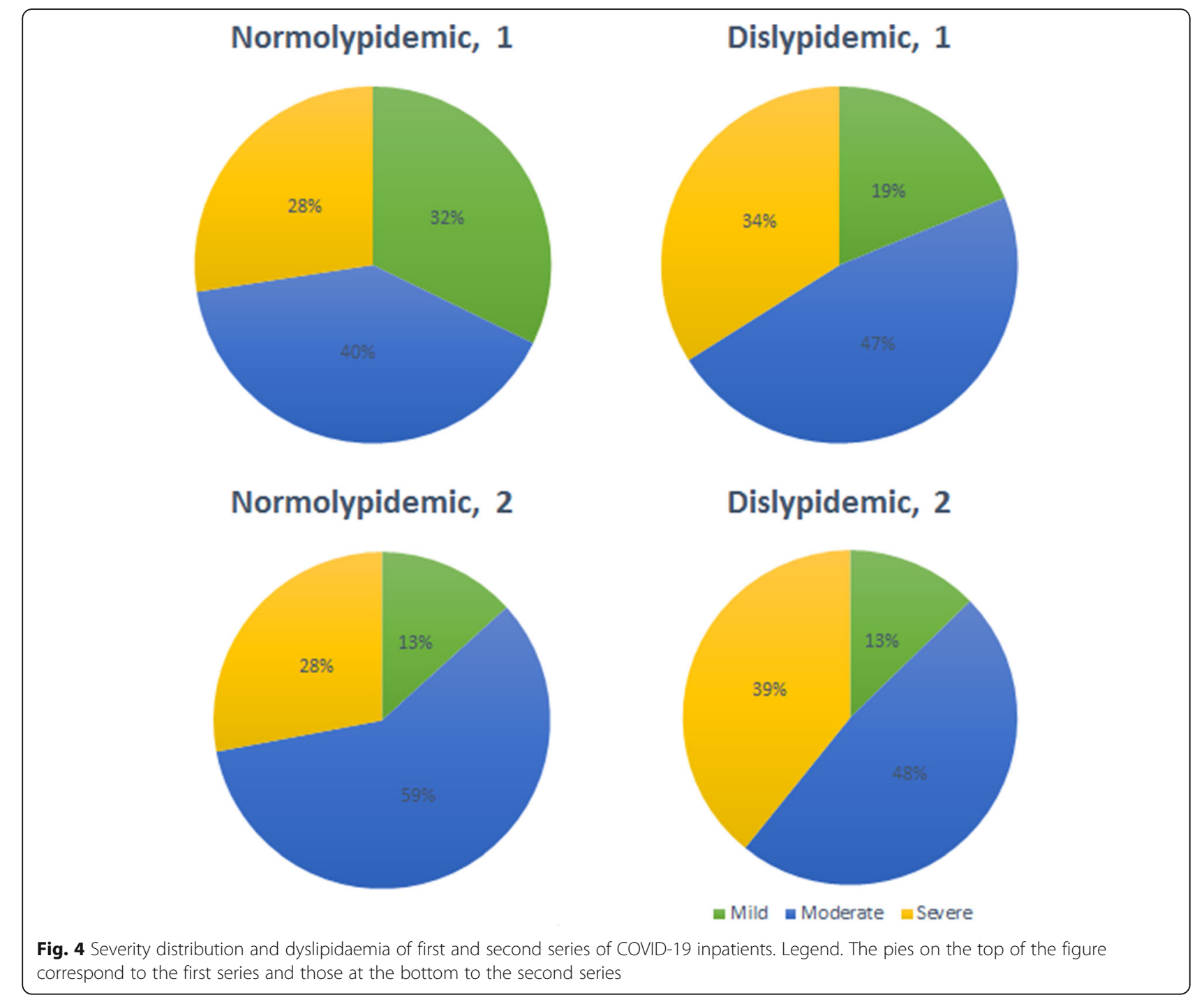

Ferritin $>200 \mathrm{ng} / \mathrm{mL}$ is also part of a model to predict patients who will need high-flow O2 input (HR 7.5) [4]. In the present study, ferritin had an AUC of 0.67 (95\% CI:0.62-0.72), and the best cut-off was much higher than those reported in the previous publications, 632.5 ng/mL (Sensitivity: 72.7\%; Specificity: 56.8\%) (Table 5). Concerning the extreme thresholds, the value $2688.5 \mathrm{ng} /$ $\mathrm{mL}$ had an LR+ of 5.51 for diagnosing severe disease and a value of $162 \mathrm{ng} / \mathrm{mL}$ had an LR- of 0.17 for discarding severe COVID-19.

Zhou et al. have proposed a D-dimer value $>1 \mathrm{mg} / \mathrm{L}$ $(1000 \mathrm{ng} / \mathrm{mL})$ (OR 18.42, 95\% CI 2.64-128.55) for COVID-19 associated mortality [19]. The optimal cut-off proposed by Tahtasakal et al. is $574 \mu \mathrm{g} / \mathrm{L}(574 \mathrm{ng} / \mathrm{mL})$ for severe COVID-19 (AUC 0.694) [23]. Elshazli et al. in a meta-analysis have found $0.48 \mu \mathrm{g} / \mathrm{L}(480 \mathrm{ng} / \mathrm{mL})$ as the optimal value for predicting severity (AUC 0.876, 95\% CI $0.868-0.884$ ) (sensitivity $88.9 \%$, specificity $77.8 \%$ ) [28]. A value of $0.65 \mathrm{mg} / \mathrm{L}(650 \mathrm{ng} / \mathrm{mL})$ has been proposed by
Zhang et al. as a predictor for severity in older adults [38]. In our study, D-dimer had an AUC of 0.62 (95\% CI:0.570.66 ) and the optimal cut-off was $1068 \mathrm{ng} / \mathrm{mL}$ (Sensitivity: 45.3\%; Specificity: 76.1\%) (Table 5). The extreme high threshold showed no utility because of their obviousness, $34,744 \mathrm{ng} / \mathrm{mL}$ with an LR+ of 4.6 for diagnosing severe disease. No D-dimer value had a reliable LR- less than 0.5 for discarding severe COVID-19.

IL-6 levels are used in the context of COVID-19 disease for patient follow-up and clinical decision-making. Several levels of IL-6 have been proposed in different studies to predict severity progression. In the metaanalysis by Elshazli et al. a cut-off point of $22.9 \mathrm{pg} / \mathrm{mL}$ obtained an AUC of 0.63 (95\% CI 0.616-0.648) (Sensitivity $71.4 \%$, Specificity $71.4 \%$ ) [28]. A similar cut-off point, $34.9 \mathrm{pg} / \mathrm{mL}$, showed an AUC of 0.760 and an OR of 12.750 (95\% CI $2.2-75.3)$ to predict ICU admission [3]. A $64 \mathrm{pg} / \mathrm{mL}$ cut-off point for IL-6 is also part of a model to predict patients who will need high-flow $\mathrm{O} 2$ 
Table 5 Diagnostic validity of laboratory parameters

\begin{tabular}{|c|c|c|c|c|c|c|c|c|}
\hline & & $A U C^{a}$ & AUC $95 \% I^{\prime} C^{b}$ & $\mathrm{LR}+{ }^{\mathrm{c}}$ & LR- $^{d}$ & $\mathrm{Yl}^{\mathrm{e}}$ & Sensitivity (\%) & Specificity (\%) \\
\hline \multicolumn{9}{|l|}{$\operatorname{IL6}^{f}(\mathrm{pg} / \mathrm{mL})$} \\
\hline Best cut-off & 69.08 & 0.70 & $0.64-0.76$ & & & 0.31 & 51.24 & 79.86 \\
\hline Best cut-off for LR+ & 175.1 & & & 5.2 & & & 28.10 & 94.60 \\
\hline Best cut-off for LR- & 5.56 & & & & 0.19 & & 97.52 & 12.59 \\
\hline \multicolumn{9}{|l|}{$\mathrm{CRP}^{\mathrm{g}}(\mathrm{mg} / \mathrm{L})$} \\
\hline Best cut-off & 97.3 & 0.67 & $0.65-0.73$ & & & 0.28 & 62.18 & 66.05 \\
\hline Best cut-off for LR+ & 291.85 & & & 5.16 & & & 14.29 & 97.23 \\
\hline Best cut-off for LR- & 7 & & & & 0.21 & & 97.90 & 11.62 \\
\hline \multicolumn{9}{|l|}{ Ferritin (ng/mL) } \\
\hline Best cut-off & 632.5 & 0.67 & $0.62-0.73$ & & & 0.29 & 72.66 & 56.79 \\
\hline Best cut-off for LR+ & 2688.5 & & & 5.51 & & & 12.23 & 87.77 \\
\hline Best cut-off for LR- & 162 & & & & 0.17 & & 97.12 & 16.62 \\
\hline \multicolumn{9}{|l|}{$\mathrm{LDH}^{\mathrm{h}}(\mathrm{U} / \mathrm{L})$} \\
\hline Best cut-off & 328.5 & 0.71 & $0.66-0.75$ & & & 0.36 & 65.58 & 70.62 \\
\hline Best cut-off for LR+ & 574 & & & 5.34 & & & 17.21 & 96.78 \\
\hline Best cut-off for LR- & 177.5 & & & & 0.3 & & 88.37 & 30.99 \\
\hline \multicolumn{9}{|l|}{ D-dimer (ng/mL) } \\
\hline Best cut-off & 1068 & 0.62 & $0.57-0.66$ & & & 0.21 & 45.28 & 76.12 \\
\hline Best cut-off for LR+ & 34,744 & & & 4.62 & & & 1.89 & 99.59 \\
\hline Best cut-off for LR- & None & & & & & & na. & na. \\
\hline \multicolumn{9}{|c|}{ 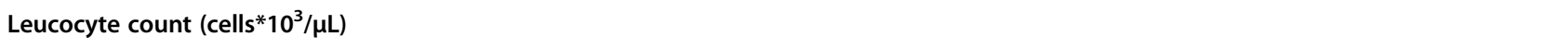 } \\
\hline Best cut-off & 7.835 & 0.62 & $0.58-0.67$ & & & 0.22 & 50.57 & 71.90 \\
\hline Best cut-off for LR+ & 15.875 & & & 5.14 & & & 9.89 & 98.08 \\
\hline Best cut-off for LR- & None & & & & & & na. & na. \\
\hline \multicolumn{9}{|c|}{ Neutrophil count (cells*10 $3 / \mu \mathrm{L}$ ) } \\
\hline Best cut-off & 6.26 & 0.66 & $0.62-0.70$ & & & 0.27 & 51.33 & 75.44 \\
\hline Best cut-off for LR+ & 13.04 & & & 5.37 & & & 12.17 & 97.74 \\
\hline Best cut-off for LR- & None & & & & & & na. & na. \\
\hline \multicolumn{9}{|c|}{ 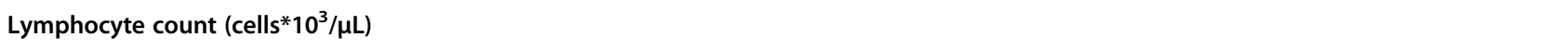 } \\
\hline Best cut-off & 0.725 & 0.61 & $0.57-0.65$ & & & 0.18 & 39.92 & 77.66 \\
\hline Best cut-off for LR+ & 0.365 & & & 5.34 & & & 10.27 & 98.08 \\
\hline Best cut-off for LR- & None & & & & & & na. & na. \\
\hline \multicolumn{9}{|c|}{ CD3 + CD4+ count (cells $/ \mu \mathrm{L})$} \\
\hline Best cut-off & 535.5 & 0.70 & $0.61-0.80$ & & & 0.41 & 90.32 & 50.51 \\
\hline Best cut-off for LR+ & 95.74 & & & 4.79 & & & 9.68 & 97.98 \\
\hline Best cut-off for LR- & 660.6 & & & & 0.16 & & 93.55 & 39.39 \\
\hline \multicolumn{9}{|c|}{ CD4 + CD8+ count (cells/ $\mu \mathrm{L})$} \\
\hline Best cut-off & 162.83 & 0.63 & $0.52-0.75$ & & & 0.22 & 58.06 & 63.64 \\
\hline Best cut-off for LR+ & None & & & & & & na. & na. \\
\hline Best cut-off for LR- & None & & & & & & na. & na. \\
\hline \multicolumn{9}{|l|}{ CD19+ count (cells/ $\mu \mathrm{L})$} \\
\hline Best cut-off & na.' & 0.59 & $0.47-0.71$ & & & na. & na. & na. \\
\hline Best cut-off for LR+ & na. & & & & & & na. & na. \\
\hline Best cut-off for LR- & na. & & & & & & na. & na. \\
\hline
\end{tabular}


Table 5 Diagnostic validity of laboratory parameters (Continued)

\begin{tabular}{|c|c|c|c|c|c|c|c|c|}
\hline & & $A \cup C^{a}$ & AUC $95 \% I^{b}$ & $\mathrm{LR}+{ }^{\mathrm{c}}$ & LR- $^{d}$ & $\mathrm{Yl}^{\mathrm{e}}$ & Sensitivity (\%) & Specificity (\%) \\
\hline \multicolumn{9}{|c|}{ Natural Killer count (cells $/ \mu \mathrm{L}$ ) } \\
\hline Best cut-off & 147.5 & 0.65 & $0.54-0.77$ & & & 0.28 & 75.00 & 53.26 \\
\hline Best cut-off for LR+ & 43.29 & & & 5.11 & & & 16.67 & 96.74 \\
\hline Best cut-off for LR- & 229.38 & & & & 0.18 & & 95.83 & 22.83 \\
\hline
\end{tabular}

Abbreviations: $A U C^{\mathrm{a}}$ Area under the curve, $A U C 96 \% I C^{\mathrm{b}} 95 \%$ Confidence Intervale of the area under the curve, $L R^{\mathrm{C}}$ Likelyhood ratio positive, $L R^{\mathrm{d}}{ }^{\mathrm{C}}$ Likelyhood ratio negative, $Y l^{\mathrm{e}}$ Youden Index, $I L \sigma^{\mathrm{f}}$ Interleukin $6, C R P^{\mathrm{g}}$ C-reactive protein, $L D H^{\mathrm{h}}$ Lactate dehydrogenase, na. ${ }^{\mathrm{i}}$ Non aplicable

input (hazard ratio 18) [4]. A higher cut-off, $163.4 \mathrm{pg} /$ $\mathrm{mL}$, has been proposed for predicting death with a 91.7\% sensitivity and $57.6 \%$ specificity [39]. In our study a value of $69.08 \mathrm{pg} / \mathrm{mL}$ has been found as a predictor of severity (AUC 0.70, 95\% CI:0.64-0.76) pg/mL (Sensitivity: 51.2\%; Specificity: 79.8\%) (Table 5). Concerning the extreme thresholds, the value $175 \mathrm{pg} / \mathrm{mL}$ had an LR+ of 5.2 for diagnosing severe disease and a value of $5.56 \mathrm{pg} /$ $\mathrm{mL}$ had an LR- of 0.19 for discarding severe COVID-19.

An elevated neutrophil count, lymphopenia, and an elevated neutrophil/Lymphocyte ratio are characteristic of severe COVID-19 [23, 28, 40]. Lymphopenia is also part of the infection pathogenesis and is both a cause and a consequence of the severity [41]. Ji et al. have proposed a cut-off point of $1 * 10^{3}$ lymphocytes $/ \mu \mathrm{L}$ for the diagnosis of severe disease (HR 3.7, 95\% CI 1.8-7.8) [20]. Tahtasakal et al. have proposed a cut-off point of $1.04^{*} 10^{3}$ cells/ $\mu \mathrm{L}$ for the diagnosis of severe disease (AUC 0.678) [23]. In a meta-analysis with 6320 patients, a cut-off point of $0.98 * 10^{3}$ cells $/ \mu \mathrm{L}$ (AUC $0.867,95 \%$ CI $0.861-0.873$ ) is proposed (sensitivity $81.2 \%$, specificity $87.5 \%$ ), as a marker of severe COVID-19 [28]. In our study, the AUC of this parameter was low 0.61 (95\% CI:0.57-0.65) and the best cut-off was 0.725 cells* $10^{3} / \mu \mathrm{L}$ (Sensitivity: 39.9\%; Specificity: 77.7\%) (Table 5). Regarding extreme thresholds, the value 0.365 cells $^{*} 10^{3} / \mu \mathrm{L}$ had an $\mathrm{LR}+$ of 5.34 for diagnosing severe disease. No lymphocyte count value had a reliable LR- under 0.5 for discarding severe COVID-19. In summary, both the low AUC and the absence of extreme values with adequate LR- mean that no reliable lymphocyte count values were found to help predict evolution in our study.

Total lymphocyte count, lymphocyte populations, especially the $\mathrm{T}$ ones, are affected in the severest cases of COVID-19. Different cut-offs for CD8+ lymphocytes have been reported. Du et al. [42] propose a cut-off point of 75 cells $/ \mu \mathrm{L}$ to predict a fatal outcome. In our study, the CD3 + CD8 + count had a low AUC of 0.63 (95\% CI:0.52-0.75) and the best cut-off was 163 cells/ $\mu \mathrm{L}$ (Sensitivity: 51.6\%; Specificity: 75\%) (Table 4). Concerning the extreme thresholds, no CD3 + CD8+ count had an acceptable $\mathrm{LR}+$ for diagnosing severe disease nor LRless than 0.5 for discarding severe COVID-19. For CD4+ T-lymphocytes, there are few studies with predictive cut-off points, Zhang et al. have proposed a cut-off point of 268 cells $/ \mu \mathrm{L}$ (AUC 0.804, 95\% CI 0.695-0.912) for predicting severe disease in older adults with COVID-19 [38]. However, in our study. CD3 + CD4+ count had an AUC of 0.70 (95\% CI:0.61-0.80) and the optimal cut-off was 535 cells/ $\mu \mathrm{L}$ (Sensitivity: 90.3\%; Specificity: 50.5\%) (Table 4). The value 95.74 cells/ $\mu \mathrm{L}$ had an $\mathrm{LR}+$ of 4.79 for diagnosing severe disease, and a value of 660.6 cells/ $\mu \mathrm{L}$ had an LR- of 0.16 for discarding severe COVID-19.

Finally, age has been ratified as a crucial factor in COVID-19 severity in our series. Age correlates with endothelial damage and coagulation dysfunction, immunosenescence, inflammaging, including the effects of chronic cytomegalovirus infection, increased prevalence of COVID-19-associated comorbidities, and low levels of vitamin D [43]. Immunosenescence refers to age-related changes in the immune system [44]. Older individuals are more susceptible to infections due to immunological changes associated with the ageing process [45]. These progressive changes affect both innate and adaptive immunity. They include a decrease in naive lymphocytes, the contraction of lymphocyte repertoire, increased memory lymphocytes, fibrotic changes in lymph node architecture, and dysregulation in cytokine production [46]. The low-grade chronic inflammatory state that accompanies ageing, called inflammaging, may predispose older adults to severe COVID-19 by impairing the immune response to SARS-CoV-2. Inflammaging is characterized by high levels of acute-phase proteins and proinflammatory cytokines [47]. It has been suggested that individuals with more severe SARS-CoV-2 infection may have a cytokine storm syndrome characterized by increased levels of cytokines and chemokines [45]. Cytokine storm in elderly with severe SARS-CoV-19 is associated with age-related pathophysiological processes, including senescent cell inflammatory phenotype, excess oxygen radical production, immunosenescence, and lack of vitamin D [48]. Endothelial damage is a critical point that allows us to identify patients prone to develop severe COVID-19. Endothelial barrier mechanisms are independently compromised by diabetes, obesity, age [49] and hypertension, that are known to determine bad COVID-19 prognosis. The hypothesis that attributes the severity of COVID-19 evolution to age-related changes 
is partly speculative, but supported by different experimental studies. Thus, Rydyznski et al., studying the specific humoral and cellular response to SARS-Cov-2, point out that age correlates with a more severe specific antigen immune response. Older individuals present an uncoordinated humoral and cellular response to SARSCoV-2. This coordination is notably affected in those over 65 years of age. T lymphocytes' shortage is associated with age and worse COVID-19 prognosis [50].

Baas et al. performing genomic analysis of the response to SARS-CoV-1 in a murine model, point out that older individuals present an exacerbated immune response and that the expression of the genes of TNF- $\alpha$, IL-6, CCL2, CCL3, CXCL10 and INF- $\gamma$ exhibit a biphasic pattern that correlates with the peak of viral replication and with the flow of lymphocytes to the areas of more severe histopathological damage in the lungs [51]. Sims et al. characterize the cytokine storm that accompanies severe COVID-19 and find a panel of markers, such as IL-6, PTX3, IL-1RA, CTSL1, IL-18 and RAGE that would reflect vascular endothelial disruption [52]. An unbalanced production of pro-inflammatory cytokines has been described in immunosenescence in healthy individuals. Thus, Shurin et al. demonstrate that INF- $\gamma$-inducible chemokines (MIG and IP-10) increase with age [53]. Concerning the above, Tincati et al. analysing the phenotype of cytokines and chemokines that characterizes the worsening of COVID-19 in the second week of the disease, point out that this critical point in the evolution of the disease is associated to higher levels of CXCL8/IL-8, CXCL-9/MIG and CXCL10/IP-10, and that the presence of circulating neutrophils is associated to these levels [54]. Likewise, Xiong et al., employing the transcriptomic analysis of the characteristics of bronchoalveolar lavage and peripheral blood mononuclear cells of individuals with COVID-19 pneumonia, point out the association between the pathogenesis of the disease and the excessive release of cytokines such as CCL2/MCP-1, CXCL10/IP-10, CCL3/MIP-1A and CCL4/MIP-1B [55]. Moreover, IP-10 (CXCL10) [56, 57] and MCP-1 [56] have been proposed as biomarkers related to the risk of death in COVID-19 [56] and severity [57]. In the autopsies of the patients who died due to COVID-19, besides the mononuclear inflammatory infiltration, the diffuse alveolar damage and the formation of hyaline membranes, the particular presence of vascular affectation with epithelial damage points to a probable direct cytopathic role of the virus stands out [58]. A hypothesis could be built, where the changes associated with ageing, such as epithelial dysfunction and changes in basal levels of cytokines and chemokines (standing out CXCL-10/IP10 and CCL2/MCP-1) would enhance an exaggerated response triggered by the direct cytopathic action of the virus on endothelium. The specific response against
SARS-CoV-2, when uncoordinated due to ageing, would contribute to a worse evolution.

\section{Conclusions}

Some reliable and informative parameter cut-offs could help clinical coping with COVID-19 but lockdown data can rise heterogeneity and should be therefore cautiously managed.

The relationship between the use of RAABs and COVID-19 severity although widely commented, is not conclusively established. Controversial results should guarantee future controlled studies.

Age plays a pivotal role in COVID-19 severity, but not other age-related comorbidities. The hypothesis can be drawn of ageing related changes (epithelial dysfunction and basal levels of cytokines and chemokines) enhancing an exacerbated response to the direct cytopathic action of SARS-CoV2 on vascular endothelium. A specific but uncoordinated immune response against SARS- CoV-2 would determine a bad COVID-19 prognosis.

\section{Methods}

\section{Study design and participants}

A retrospective multicentre analysis was performed on a consecutive set of SARS-CoV-2 infected inpatients, microbiologically confirmed by positive polymerase chain reaction (CRP) test, admitted to the 13 hospitals, during May 2020. Cases were tracked for a five-week follow-up period from admission to discharge. A minimum sample size of 20 patients was considered for every hospital. A total of 260 individuals over 18 years old, from 13 Spanish hospitals were recruited. After data quality assessment, 257 patients were included in the analyses. Cases were stratified into three severity groups, when recorded for inclusion in this study according to the following criteria, adapted from the technical document published by the World Health Organization [59].

- Mild: whenever clinical symptoms were mild with no abnormal radiological findings.

- Moderate: cases with confirmed pneumonia that was not considered severe

- Severe: when at least one of the following criteria was met: acute respiratory distress, shock, admission to the intensive care unit (ICU), the process was so considered by the physician in charge. Any death was as well classified as severe.

This retrospective observational study was conducted according to national regulations, institutional policies and in the tenets of the Helsinki Declaration. It was approved by the local institutional Ethics Committee of any involved hospitals. 
Data from 584 case records from the previously analysed series [16], were compared with data from the 257 cases in the present study and both were pooled to explore cut-off values.

\section{Data collection}

Any data analysed were extracted from electronic medical records. The collection form included demographic, epidemiological and clinical data: age, sex, history of diabetes mellitus (DM), dyslipidaemia, hypertension (HTA), renin-angiotensin-aldosterone system blockers (RAASBs) and statins intake, the smoking status, obesity, time from onset to diagnosis, laboratory data on admission, and COVID-19 severity using the criteria previously defined.

Additionally, data from a former study conducted by our group the pre-confinement phase [16] were compared to those in the current study and merged for cutoff analyses. Inclusion and severity criteria were the same for both cohorts.

\section{Laboratory data}

Major laboratory markers were extracted from medical records on admission. Routine blood examinations included leukocyte, neutrophil and lymphocyte counts (cells $/ \mu \mathrm{L})$ and percentages. Serum biochemical tests recorded were ferritin $(\mu \mathrm{g} / \mathrm{L})$, lactate dehydrogenase (LDH, $\mathrm{U} / \mathrm{L}), \mathrm{C}$ - reactive protein $(\mathrm{CRP})$ and $\mathrm{D}$-dimer $(\mu \mathrm{g} / \mathrm{L})$. Immunological tests recorded were interleukin-6 (IL6, pg/ $\mathrm{mL})$, Lymphocyte population count (cells $/ \mu \mathrm{L})$ and percentage, complement factors $\mathrm{C} 3$ and $\mathrm{C} 4$ and immunoglobulins $\operatorname{IgG}$, IgA and $\operatorname{IgM}(\mathrm{mg} / \mathrm{dL})$.

\section{Statistical analysis}

Demographic and clinical characteristics of patients were expressed as their mean and standard deviation (SD); when not adjusting to a normal distribution, the median was used to represent non-parametric data for continuous variables and frequency distributions represented categorical variables.

Kolmogorov-Smirnov test was performed on each continuous variable to contrast normality. To analyse the overall differences between the three groups: mild, moderate, and severe type, the ANOVA was tested on variables with normal distribution and $n>30$ (\% and CD4 lymphocyte count, \% of CD8 lymphocytes, \% of NK and C3 concentration). The Kruskal-Wallis test was used to analyse the relationship with severity for non-parametric variables. To contrast the "Ho" of independence within categorical variables, Chi-square and Fisher's exact test were used.

A comparison of data collected during the lockdown period with our published data collected outside the lockdown [16] was performed as independent samples' Wilcoxon test for medians.
Pooling data from the two series searching for predictive cut-off values: We have previously published the association of laboratory parameters with severity from a cohort of COVID-19 hospitalized patients before complete lockdown. We merged the data from this cohort with those obtained during our country home confinement. To determine the diagnostic validity of each laboratory parameter, sensitivity, specificity, the receiver operating curve (ROC), the area under the curve (AUC) and the optimal cut-off (Youden index) were calculated. The maximum value of the Youden index can be used as a criterion for selecting the optimal cut-off value when a diagnostic test is expressed as a numerical value [60]. Moreover, to maximize the specificity (to rule in severe COVID-19) and the sensitivity (to rule out severe COVID-19), likelihood ratio positive and negative were calculated. A diagnostic test will be more beneficial to the extent that its positive likelihood ratio $(+\mathrm{LR})$ is of greater magnitude since it allows confirming with certainty the presence of disease, and its -LR has a low value since it rules out the disease [61].

\section{Abbreviations}

ACEls: Angiotensin-converting enzyme inhibitors; ARBs: Angiotensin II receptor blockers; RAASB: Renin-angiotensin-aldosterone system blockers; LDH: Lactate dehydrogenase; CRP: C- reactive protein; IL-6: Interleukin-6; NK: Natural Killers; IgG: Immunoglobulin G; IgA: Immunoglobulin A; IgM: Immunoglobulin M; PCR: Polymerase chain reaction; SD: Standard deviation; IQR: Interquartile range; ROC: Receiver operating curve; AUC: Area under the curve; LR: Likelihood ratio

\section{Supplementary Information}

The online version contains supplementary material available at https://doi. org/10.1186/s12979-021-00237-w.

Additional file 1: Supplementary Table 1. Comparison between Phases I and II for clinical and demographic characteristics.

Additional file 2: Supplementary Table 2. Comparison between Phases I and II for Age and Laboratory results.

\section{Acknowledgements}

The authors thank all caregivers who indirectly contributed to this multicentre study. They also thank the Spanish Society for Immunology (Sociedad Española de Inmunología, SEI) for its support and endorsement.

\section{Authors' contributions}

MCM and AJ conceived the idea for this study, designed the protocol, analysed the data and drafted the manuscript. The remaining authors collected the data, and assessed for data quality. All authors provided critical revisions and approved the final version of the manuscript.

\section{Funding}

This work has been carried out without funding.

\section{Availability of data and materials}

All collected data, including fully anonymized participant data, are available to others. Available information includes fully anonymized participant data and data dictionary. Related documents are available from the date of publications henceforth: study protocol, statistical analysis, and approval of the ethical board. These documents are available from the date of publications henceforth at email address cmartinalo@saludcastillayleon.es or aurora.jurado.sspa@juntadeandalucia.es 
Data will be shared after approval of proposals by the Valladolid Este Ethical Committee.

\section{Declarations}

\section{Ethics approval and consent to participate}

This study was conducted according to national regulations, institutional policies, and in the tenets of the Helsinki Declaration. This study was approved, with the Valladolid Health Area Drug Research Ethics Committee acting as the main committee, in a meeting held on March 31, 2020, and with the reference number "PI 20-172-NO-HCU". Moreover, it was approved by each of the local institutional Ethics Committee of the 19 hospitals involved.

\section{Competing interests}

The authors stated no conflicts of interest.

\section{Author details}

'Centro de Hemoterapia y Hemodonación de Castilla y León, Valladolid, Spain. ${ }^{2}$ Department of Immunology and Allergology, Hospital Universitario Reina Sofía-Instituto de Investigación Biomédica de Córdoba (IMIBIC), Avd. Menéndez Pidal s/n, 14004 Córdoba, Spain. ${ }^{3}$ Department of Microbiology and Immunology, Hospital Clínico Universitario, Valladolid, Spain. ${ }^{4}$ Department of Immunology, Hospital Universitario Son Espases-Human Immunopathology Research Laboratory, Institut d'Investigació Sanitària de les Illes Balears (IdISBa), Palma de Mallorca, Spain. ${ }^{5}$ Department of Immunology, Hospital Clínico Universitario, Salamanca, Spain. 'Department of Immunology, Fundación Jiménez Díaz, Madrid, Spain. ${ }^{7}$ Department of Immunology, Hospital Universitario de Badajoz, Badajoz, Spain. ${ }^{8}$ Department of Immunology, Hospital Universitario Marqués de Valdecilla, Santander, Spain. ${ }^{9}$ Laboratory of Immunology, Complejo Hospitalario Nuestra Señora de la Candelaria, Santa Cruz de Tenerife, Spain. ${ }^{10}$ Laboratoy of Immunology and Genetics, Hospital San Pedro de Alcántara, Cáceres, Spain. ${ }^{11}$ Department of Immunology, Hospital Germans Trias i Pujols, Barcelona, Spain. ${ }^{12}$ Department of Immunology, Hospital de Cruces, Baracaldo, Spain. ${ }^{13}$ Department of Immunology, Hospital Universitario La Princesa, Madrid, Spain. ${ }^{14}$ Department of Immunology, Hospital Torrecárdenas, Almería, Spain. ${ }^{15}$ Department of Immunology, Hospital de Donostia, San Sebastián, Spain. ${ }^{16}$ Unit of Immunology, Hospital General Universitario, Albacete, Spain. ${ }^{17}$ Laboratory Unit, Hospital General, Alicante, Spain. ${ }^{18}$ Department of Immunology, Complejo Hospitalario, La Coruña, Spain. ${ }^{19}$ Unit of Immunology, Hospital Universitario Insular-Materno Infantil, Las Palmas de Gran Canaria, Spain. ${ }^{20}$ Department of Immunology, Hospital General Universitario e Instituto de Investigación Sanitaria, "Gregorio Marañón", Madrid, Spain. ${ }^{21}$ Department of Immunology, Hospital Universitario Vall d'Hebron, Barcelona, Spain.

${ }^{22}$ Laboratory Unit, Hospital Juan Ramón Jiménez, Huelva, Spain. ${ }^{23}$ Laboratory Unit, Complejo Hospitalario, Jaén, Spain.

\section{Received: 10 February 2021 Accepted: 11 May 2021}

\section{Published online: 20 May 2021}

\section{References}

1. Du Toit A. Outbreak of a novel coronavirus. Nat Rev Microbiol. 2020;18(3): 123. https://doi.org/10.1038/s41579-020-0332-0.

2. COVID-19 Dashboard by the Center for Systems Science and Engineering (CSSE) at Johns Hopkins University (JHU). https://coronavirus.jhu.edu/map. html. Accessed 3 May 2021.

3. Guirao JJ, Cabrera CM, Jiménez N, Rincón L, Urra JM. High serum IL-6 values increase the risk of mortality and the severity of pneumonia in patients diagnosed with COVID-19. Mol Immunol. 2020;128:64-8. https://doi.org/10.1 016/j.molimm.2020.10.006.

4. Riveiro-Barciela M, Labrador-Horrillo M, Camps-Relats L, González-Sans D, Ventura-Cots M, Terrones-Peinador M, et al. Simple predictive models identify patients with COVID-19 pneumonia and poor prognosis. PLoS One. 2020;15(12):e0244627. https://doi.org/10.1371/journal.pone.0244627.

5. Fang L, Karakiulakis G, Roth M. Are patients with hypertension and diabetes mellitus at increased risk for COVID-19 infection? Lancet Respir Med. 2020; 8(4):e21. https://doi.org/10.1016/S2213-2600(20)30116-8.

6. Hanff TC, Harhay MO, Brown TS, Cohen JB, Mohareb AM. Is there an association between COVID-19 mortality and the renin-angiotensin system—a call for epidemiologic investigations. Clin Infect Dis. 2020:ciaa329. https://doi.org/10.1093/cid/ciaa329.

7. Zheng F, Tang W, Li H, Huang YX, Xie YL, Zhou ZG. Clinical characteristics of 161 cases of coronavirus disease 2019 [COVID-19] in Changsha. Eur Rev Med Pharmacol Sci. 2020;24(6):3404-10. https://doi.org/10.26355/eurrev_202 003_20711.

8. Liang WH, Guan WJ, Li CC, Li YM, Liang HR, Zhao Y, et al. Clinical characteristics and outcomes of hospitalized patients with COVID-19 treated in Hubei [epicenter] and outside Hubei [non-epicenter]: a nationwide analysis of China. Eur Respir J. 2020;55(6):2000562. https://doi.org/10.1183/13 993003.00562-2020.

9. Tian S, Hu N, Lou J, Chen K, Kang X, Xiang Z, et al. Characteristics of COVID19 infection in Beijing. J Inf Secur. 2020;80(4):401-6.

10. Feng Y, Ling Y, Bai T, Xie Y, Huang J, Li J. COVID-19 with different severity: a multi-centre study of clinical features. Am J Respir Crit Care Med. 2020; 201(11):1380-8. https://doi.org/10.1164/rccm.202002-0445OC.

11. Zhou F, Yu T, Du R, Fan G, Liu Y, Liu Z, et al. Clinical course and risk factors for mortality of adult inpatients with COVID-19 in Wuhan, China: a retrospective cohort study. Lancet. 2020;395(10229):1054-62.

12. Li LQ, Huang T, Wang YQ, Wang ZP, Liang Y, Huang TB. COVID-19 patients' clinical characteristics, discharge rate, and fatality rate of meta-analysis. J Med Virol. 2020. https://doi.org/10.1002/jmv.25757.

13. Wu C, Chen X, Cai Y, Xia J, Zhou X, Xu S, et al. Risk factors associated with acute respiratory distress syndrome and death in patients with coronavirus disease 2019 pneumonia in Wuhan, China. JAMA Intern Med. 2020;13. https://doi.org/10.1001/jamainternmed.2020.0994.

14. Cao J, Tu WJ, Cheng W, Yu L, Liu YK, Hu X. Clinical features and short-term outcomes of 102 patients with coronavirus disease 2019 in Wuhan, China. Clin Infect Dis. 2020. https://doi.org/10.1093/cid/ciaa243.

15. Grasselli G, Zangrillo A, Zanella A, Antonelli M, Cabrini L, Castelli A. Baseline characteristics and outcomes of 1591 patients infected with SARS-CoV-2 admitted to ICUs of the Lombardy region, Italy. JAMA. 2020;323(16):157481. https://doi.org/10.1001/jama.2020.5394.

16. Jurado A, Martín MC, Abad-Molina C, Orduña A, Martínez A, Ocaña E, et al. COVID-19: age, Interleukin-6, C-reactive protein, and lymphocytes as key clues from a multicentre retrospective study. Immun Ageing. 2020;17(1):22. https://doi.org/10.1186/s12979-020-00194-W.

17. Mudatsir M, Fajar JK, Wulandari L, Soegiarto G, Ilmawan M, Purnamasari $Y$, et al. Predictors of COVID-19 severity: a systematic review and meta-analysis. F1000Res. 2020;9:1107.

18. Setiati S, Harimurti K, Safitri ED, Ranakusuma RW, Saldi SRF, Azwar MK, et al. Risk factors and laboratory test results associated with severe illness and mortality in COVID-19 patients: a systematic review. Acta Med Indones. 2020;52(3):227-45.

19. Zhou F, Yu T, Du R, Fan G, Liu Y, Liu Z, et al. Clinical course and risk factors for mortality of adult inpatients with COVID-19 in Wuhan, China: a retrospective cohort study. Lancet. 2020;395(10229):1054-62 Erratum in: Lancet. 2020 Mar 28;395(10229):1038.

20. Ji D, Zhang D, Xu J, Chen Z, Yang T, Zhao P, et al. Prediction for progression risk in patients with COVID-19 pneumonia: the CALL score. Clin Infect Dis. 2020;71(6):1393-9. https://doi.org/10.1093/cid/ciaa414.

21. Wu G, Yang P, Xie Y, Woodruff HC, Rao X, Guiot J, et al. Development of a clinical decision support system for severity risk prediction and triage of COVID-19 patients at hospital admission: an international multicentre study. Eur Respir J. 2020;56(2):2001104.

22. Weng Z, Chen Q, Li S, Li H, Zhang Q, Lu S, et al. ANDC: an early warning score to predict mortality risk for patients with coronavirus disease 2019. J Transl Med. 2020;18(1):328. https://doi.org/10.1186/s12967-020-02505-7.

23. Tahtasakal CA, Oncul A, Sevgi DY, Celik E, Ocal M, Turkkan HM, et al. Could we predict the prognosis of the COVID-19 disease? J Med Virol. 2020. https://doi.org/10.1002/jmv.26751.

24. Diao B, Wang C, Tan Y, Chen X, Liu Y, Ning L, et al. Reduction and functional exhaustion of $T$ cells in patients with coronavirus disease 2019 (COVID-19). Front Immunol. 2020. https://doi.org/10.3389/fimmu-2020.00827.

25. Qin C, Zhou L, Hu Z, Zhang S, Yang S, Tao Y. Dysregulation of immune response in patients with COVID-19 in Wuhan, China. Clin Infect Dis. 2020. https://doi.org/10.1093/cid/ciaa248.

26. Koff WC, Williams MA. COVID-19 and immunity in aging populations. A new research agenda. N Engl J Med. 2020. https://doi.org/10.1056/NEJMp2006761.

27. Moutchia J, Pokharel P, Kerri A, McGaw K, Uchai S, Nji M, et al. Clinical laboratory parameters associated with severe or critical novel coronavirus 
disease 2019 (COVID-19): a systematic review and meta-analysis. PLoS One. 2020;15(10):e0239802. https://doi.org/10.1371/journal.pone.0239802.

28. Elshazli RM, Toraih EA, Elgaml A, El-Mowafy M, El-Mesery M, Amin MN, et al. Diagnostic and prognostic value of hematological and immunological markers in COVID-19 infection: a meta-analysis of 6320 patients. PLoS One. 2020;15(8):e0238160. https://doi.org/10.1371/journal.pone.0238160.

29. Akbari H, Tabrizi R, Lankarani KB, Aria H, Vakili S, Asadian F, et al. The role of cytokine profile and lymphocyte subsets in the severity of coronavirus disease 2019 (COVID-19): a systematic review and meta-analysis. Life Sci. 2020:258:118167. https://doi.org/10.1016/.lffs.2020.118167.

30. Huang W, Berube J, McNamara M, Saksena S, Hartman M, Arshad T, et al. Lymphocyte subset counts in COVID-19 patients: a meta-analysis. Cytometry A. 2020;97(8):772-6. https://doi.org/10.1002/cyto.a.24172.

31. Pirola CJ, Sookoian S. Estimation of renin-angiotensin-aldosterone-system (RAAS)-inhibitor effect on COVID-19 outcome: a meta-analysis. J Inf Secur. 2020;81(2):276-81.

32. Patoulias D, Katsimardou A, Stavropoulos K, Imprialos K, Kalogirou MS, Doumas M. Renin-angiotensin system inhibitors and COVID-19: a systematic review and meta-analysis. Evidence for significant geographical disparities. Curr Hypertens Rep. 2020;22(11):90.

33. Megaly M, Glogoza M. Renin-angiotensin system antagonists are associated with lower mortality in hypertensive patients with COVID-19. Scott Med J. 2020;65(4):123-6. https://doi.org/10.1177/0036933020949219.

34. Chan CK, Huang YS, Liao HW, Tsai IJ, Sun CY, Pan HC, et al. Reninangiotensin-aldosterone system inhibitors and risks of severe acute respiratory syndrome coronavirus 2 infection: a systematic review and metaanalysis. Hypertension. 2020;76(5):1563-71. https://doi.org/10.1161/ HYPERTENSIONAHA. 120.15989.

35. Li C, Ye J, Chen Q, Hu W, Wang L, Fan Y, et al. Elevated lactate dehydrogenase ( $\mathrm{LDH}$ ) level as an independent risk factor for the severity and mortality of COVID-19. Aging (Albany NY). 2020;12(15):15670-81. https://doi.org/10.18632/aging.103770.

36. Poggiali E, Zaino D, Immovilli P, Rovero L, Losi G, Dacrema A, et al. Lactate dehydrogenase and $\mathrm{C}$-reactive protein as predictors of respiratory failure in COVD19 patients. Clin Chim Acta. 2020;509:135-8. https//doi.org/10.1016/j.cca.2020.06.012.

37. Cheng B, Hu J, Zuo X, Chen J, Li X, Chen Y, et al. Predictors of progression from moderate to severe coronavirus disease 2019: a retrospective cohort. Clin Microbiol Infect. 2020;26(10):1400-5. https:// doi.org/10.1016/j.cmi.2020.06.033.

38. Zhang XY, Zhang L, Zhao Y, Chen L. Risk assessment and prediction of severe or critical COVID-19 illness in older adults. Clin Interv Aging. 2020;15: 2145-53. https://doi.org/10.2147/CIA.S268156.

39. Mandel M, Harari G, Gurevich M, Achiron A. Cytokine prediction of mortality in COVID-19 patients. Cytokine. 2020;134:155190. https://doi.org/10.1016/j. cyto.2020.155190.

40. Wang C, Deng R, Gou L, Fu Z, Zhang X, Shao F, et al. Preliminary study to identify severe from moderate cases of COVID-19 using combined hematology parameters. Ann Transl Med. 2020;8(9):593. https://doi.org/10.21 037/atm-20-3391.

41. Jin M, Shi N, Wang M, Shi C, Lu S, Chang Q, et al. CD45: a critical regulator in immune cells to predict severe and non-severe COVID-19 patients. Aging (Albany NY). 2020;12(20):19867-79.

42. Du RH, Liang LR, Yang CQ, Wang W, Cao TZ, Li M, et al. Predictors of mortality for patients with COVID-19 pneumonia caused by SARS-CoV-2: a prospective cohort study. Eur Respir J. 2020:55(5):2000524.

43. Zimmermann P, Curtis N. Why is COVID-19 less severe in children? A review of the proposed mechanisms underlying the age-related difference in severity of SARS-CoV-2 infections. Arch Dis Child. 2020:archdischild-2020-320338. https:// doi.org/10.1136/archdischild-2020-320338. Epub ahead of print.

44. Pera A, Campos C, López N, Hassouneh F, Alonso C, Tarazona R, et al. Immunosenescence: implications for response to infection and vaccination in older people. Maturitas. 2015;82(1):50-5. https://doi.org/10.1016/.maturitas.2015.05.004.

45. Pietrobon AJ, Teixeira FME, Sato MN. Immunosenescence and Inflammaging: risk factors of severe COVID-19 in older people. Front Immunol. 2020;11:579220. https://doi.org/10.3389/fimmu.2020.579220.

46. Crooke SN, Ovsyannikova IG, Poland GA, Kennedy RB. Immunosenescence and human vaccine immune responses. Immun Ageing. 2019;16(1):25. https://doi.org/10.1186/s12979-019-0164-9.

47. Hazeldine J, Lord JM. Immunesenescence: a predisposing risk factor for the development of COVID-19? Front Immunol. 2020;11:573662. https://doi. org/10.3389/fimmu.2020.573662.
48. Meftahi GH, Jangravi Z, Sahraei H, Bahari Z. The possible pathophysiology mechanism of cytokine storm in elderly adults with COVID-19 infection: the contribution of "inflame-aging". Inflamm Res. 2020;69(9):825-39. https://doi. org/10.1007/s00011-020-01372-8.

49. Hanchard J, Capó-Vélez CM, Deusch K, Lidington D, Bolz SS. Stabilizing cellular barriers: raising the shields against COVID-19. Front Endocrinol (Lausanne). 2020;1 1:583006.

50. Rydyznski Moderbacher C, Ramirez SI, Dan JM, Grifoni A, Hastie KM, Weiskopf $\mathrm{D}$, et al. Antigen-specific adaptive immunity to SARS-CoV-2 in acute COVID-19 and associations with age and disease severity. Cell. 2020; 183(4):996-1012.e19.

51. Baas T, Roberts A, Teal TH, Vogel L, Chen J, Tumpey TM, et al. Genomic analysis reveals age-dependent innate immune responses to severe acute respiratory syndrome coronavirus. J Virol. 2008;82(19):9465-76. https://doi. org/10.1128/JVI.00489-08

52. Sims JT, Krishnan V, Chang CY, Engle SM, Casalini G, Rodgers GH, et al. Characterization of the cytokine storm reflects hyperinflammatory endothelial dysfunction in COVID-19. J Allergy Clin Immunol. 2021;147(1): 107-11. https://doi.org/10.1016/j.jaci.2020.08.031

53. Shurin GV, Yurkovetsky ZR, Chatta GS, Tourkova IL, Shurin MR, Lokshin AE. Dynamic alteration of soluble serum biomarkers in healthy aging. Cytokine. 2007:39(2):123-9. https://doi.org/10.1016/j.cyto.2007.06.006.

54. Tincati C, Cannizzo ES, Giacomelli M, Badolato R, d'Arminio Monforte A, et al. Heightened circulating interferon-inducible chemokines, and activated pro-Cytolytic Th1-cell phenotype features COVID-19 aggravation in the second week of illness. Front Immunol. 2020;11:580987. https://doi.org/10.33 89/fimmu.2020.580987.

55. Xiong Y, Liu Y, Cao L, Wang D, Guo M, Jiang A, et al. Transcriptomic characteristics of bronchoalveolar lavage fluid and peripheral blood mononuclear cells in COVID-19 patients. Emerg Microbes Infect. 2020;9(1): 761-70. https://doi.org/10.1080/22221751.2020.1747363.

56. Chen Y, Wang J, Liu C, Su L, Zhang D, Fan J, et al. IP-10 and MCP-1 as biomarkers associated with disease severity of COVID-19. Mol Med. 2020; 26(1):97. https://doi.org/10.1186/s10020-020-00230-x.

57. Lev S, Gottesman T, Sahaf Levin G, Lederfein D, Berkov E, Diker DO, et al. Observational cohort study of IP-10's potential as a biomarker to aid in inflammation regulation within a clinical decision support protocol for patients with severe COVID-19. PLoS One. 2021;16(1):e0245296. https://doi. org/10.1371/journal.pone.0245296.

58. Calabrese F, Pezzuto F, Fortarezza F, Hofman P, Kern I, Panizo A, et al. Pulmonary pathology and COVID-19: lessons from autopsy. The experience of European pulmonary pathologists. Virchows Arch. 2020;477(3):359-72 https://doi.org/10.1007/s00428-020-02886-6

59. World Health Organization. Clinical management of COVID-19: interim guidance, 27 May 2020. https://apps.who.int/iris/handle/10665/332196. Accessed 3 May 2021.

60. Youden WJ. Index for rating diagnostic tests. Cancer. 1950;3(1):32-5. https:// doi.org/10.1002/1097-0142(1950)3:1<32:"AID-CNCR2820030106>3.0.CO;2-3.

61. Pauker SG, Kassirer JP. Therapeutic decision making: a cost-benefit analysis. N Engl J Med. 1975;293(5):229-34. https://doi.org/10.1056/ NEJM197507312930505.

\section{Publisher's Note}

Springer Nature remains neutral with regard to jurisdictional claims in published maps and institutional affiliations.

Ready to submit your research? Choose BMC and benefit from:

- fast, convenient online submission

- thorough peer review by experienced researchers in your field

- rapid publication on acceptance

- support for research data, including large and complex data types

- gold Open Access which fosters wider collaboration and increased citations

- maximum visibility for your research: over $100 \mathrm{M}$ website views per year

At BMC, research is always in progress.

Learn more biomedcentral.com/submission 